\title{
The Endogenous Cannabinoid System: A Budding Source of Targets for Treating Inflammatory and Neuropathic Pain
}

\author{
Giulia Donvito ${ }^{1}$, Sara R Nass ${ }^{2}$, Jenny L Wilkerson ${ }^{1}$, Zachary A Curry ${ }^{1}$, Lesley D Schurman ${ }^{1}$, \\ Steven G Kinsey ${ }^{2}$ and Aron H Lichtman*,1 \\ ${ }^{1}$ Department of Pharmacology and Toxicology, Medical College of Virginia Campus, Virginia Commonwealth University, \\ Richmond, VA, USA; ${ }^{2}$ Department of Psychology, West Virginia University, Morgantown, WV, USA
}

\begin{abstract}
A great need exists for the development of new medications to treat pain resulting from various disease states and types of injury. Given that the endogenous cannabinoid (that is, endocannabinoid) system modulates neuronal and immune cell function, both of which play key roles in pain, therapeutics targeting this system hold promise as novel analgesics. Potential therapeutic targets include the cannabinoid receptors, type 1 and 2, as well as biosynthetic and catabolic enzymes of the endocannabinoids $\mathrm{N}$-arachidonoylethanolamine and 2-arachidonoylglycerol. Notably, cannabinoid receptor agonists as well as inhibitors of endocannabinoid-regulating enzymes fatty acid amide hydrolase and monoacylglycerol lipase produce reliable antinociceptive effects, and offer opioid-sparing antinociceptive effects in myriad preclinical inflammatory and neuropathic pain models. Emerging clinical studies show that 'medicinal' cannabis or cannabinoid-based medications relieve pain in human diseases such as cancer, multiple sclerosis, and fibromyalgia. However, clinical data have yet to demonstrate the analgesic efficacy of inhibitors of endocannabinoid-regulating enzymes. Likewise, the question of whether pharmacotherapies aimed at the endocannabinoid system promote opioid-sparing effects in the treatment of pain reflects an important area of research. Here we examine the preclinical and clinical evidence of various endocannabinoid system targets as potential therapeutic strategies for inflammatory and neuropathic pain conditions.
\end{abstract}

Neuropsychopharmacology Reviews (2018) 43, 52-79; doi:10.1038/npp.2017.204; published online 8 November 2017

\section{INTRODUCTION}

Chronic pain, such as inflammatory or neuropathic pain, represents a complicated condition that not only diminishes quality of life but also comes at great economic cost. The mechanisms of pathological pain are complex and characterized by both peripheral and central neuronal alterations and neuroimmune activation, which modulates in the initiation and maintenance of chronic pain. Glial cells, including microglia, astrocytes, and oligodendrocytes, located within the central nervous system (CNS), as well as Schwann cells located in the peripheral nervous system (PNS), modulate inflammation after nerve injury (Machelska and Celik, 2016). Following injury, neuronal inflammation and reparatory mechanisms of neural tissues induce a state of peripheral hyperexcitability in primary afferent nociceptors. Additionally, these peripheral nociceptors synapse with

${ }^{*}$ Correspondence: Dr AH Lichtman, Department of Pharmacology and Toxicology, Medical College of Virginia Campus, Virginia Commonwealth University, Richmond, VA 23298-0613, USA, Tel: +804 828 8480, Fax: +804828 2117, E-mail: aron.lichtman@vcuhealth.org

Received 10 April 2017; revised 24 August 2017; accepted 27 August 2017; accepted article preview online 31 August 2017 neurons found within the dorsal horn of the spinal cord that undergo dramatic functional alterations, due to the loss of activity of inhibitory neurons. When this loop persists in an enduring way, it results in a persistent pain, which is often resistant to treatments. Indeed, the lack of efficacy of conventional pharmacotherapies to reduce pain, and the significant side effects associated with available medications, creates an unmet need, which has fueled drug discovery efforts for novel analgesics.

A large body of preclinical research demonstrates the effectiveness of cannabinoids in rodent models of acute and chronic inflammatory pain, as well as neuropathic pain (Richardson, 2000). In comparison, few published studies have examined the antinociceptive effects of cannabinoids in nonhuman primates. In the rhesus monkey warm water tail withdrawal paradigm, the endogenous cannabinoid arachidonoylethanolamine (anandamide; AEA), the primary active constituent of cannabis $\Delta^{9}$-tetrahydrocannabinol (THC), and the high efficacy synthetic cannabinoid receptor agonist WIN55,212-2 produce dose-dependent antinociceptive effects (Manning et al, 2001; Vivian et al, 1998). Other studies also demonstrate that THC and another high efficacy 
cannabinoid receptor agonist, CP55,940, evoke antinociceptive effects in rhesus monkeys (Li et al, 2008; Maguire and France, 2014, 2016).

Several clinical studies have demonstrated the analgesic effects of cannabinoids in human disease states, including pain associated with diabetes, chemotherapy, multiple sclerosis, and fibromyalgia (Lynch and Ware, 2015; Whiting et al, 2015). However, cannabinoids lack efficacy for acute pain (for example, dental pain, postoperative pain, and so on (Stevens and Higgins, 2017)). The primary psychoactive constituent of cannabis, THC (Mechoulam and Gaoni, 1965), and certain other plant-derived or synthetic psychoactive cannabinoids bind cannabinoid $\left(\mathrm{CB}_{1}\right.$ and $\left.\mathrm{CB}_{2}\right)$ receptors (Devane et al, 1988; Matsuda et al, 1990; Munro et al, 1993). These cannabinoid receptors belong to the $G$ protein-coupled superfamily and are heterogeneously distributed throughout the CNS and $\mathrm{PNS}$. $\mathrm{CB}_{1}$ receptors are highly expressed on presynaptic neurons in the brain (Tsou et al, 1998), spinal cord (Farquhar-Smith et al, 2000), and dorsal root ganglia (Hohmann and Herkenham, 1999; Sañudo-Peña et al, 1999). In contrast, $\mathrm{CB}_{2}$ receptors are primarily expressed in immune cells, including myeloid, macrophage, microglia, lymphoid, and mast cells (Piomelli, 2003). Expression of endocannabinoid receptors on various CNS cell types is shown in Figure 1.

The most studied endogenous ligands that bind cannabinoid receptors are AEA (Devane et al, 1992) and 2arachidonoylglycerol (2-AG) (Mechoulam et al, 1995; Sugiura et al, 1995). Although several biosynthetic pathways have been proposed for AEA production, rate-limiting biosynthetic enzyme(s) remain to be identified (Blankman and Cravatt, 2013). In contrast, diacylglycerol lipase (DAGL) $\alpha$ and $\beta$ transform diacylglycerols into 2-AG (Bisogno et al, 2003; Gao et al, 2010; Tanimura et al, 2010). AEA and 2-AG are rapidly hydrolyzed by fatty acid amide hydrolase (FAAH) (Cravatt et al, 1996, 2001), and monoacylglycerol lipase (MAGL) (Dinh et al, 2002), respectively. Besides serving as the major catabolic enzyme of AEA, FAAH hydrolyzes other bioactive lipids, such as $\mathrm{N}$-palmitoylethanolamine (PEA) (Fezza et al, 2008), which does not bind cannabinoid receptors, but functions as an endogenous ligand for peroxisome proliferator receptor- $\alpha$ (PPAR- $\alpha$ ) (Lo Verme et al, 2005). In addition to being the primary hydrolytic enzyme for 2-AG (Dinh et al, 2002), MAGL is a rate-limiting enzyme in the production of free arachidonic acid in brain, liver, and lung, but not in the gastrointestinal tract or other organs (Nomura et al, 2011). Thus, MAGL inhibitors can produce antinociceptive and anti-inflammatory actions through increased levels of 2-AG-stimulating cannabinoid receptors, and decreased levels of arachidonic acid and its pro-inflammatory metabolites. A schematic representation of key endocannabinoid-regulating enzymes is presented in Figure 2.

Here we review current knowledge regarding the antinociceptive effects of cannabinoids in inflammatory and neuropathic preclinical studies of pain as well as clinical evaluations. It is noteworthy that there is a growing interest in potential therapeutic effects of another cannabis constituent, cannabidiol (CBD), which is included in Sativex, a drug containing approximately equal parts of THC and CBD. Preclinical studies testing combinations of THC and CBD, as well as clinical studies using Sativex to demonstrate antiinflammatory (Lodzki et al, 2003; Malfait et al, 2000; Xiong et al, 2012) and antinociceptive effects (King et al, 2017; Langford et al, 2013; Lehmann et al, 2017; Serpell et al, 2014; Ward et al, 2014) are reported in the literature. However, as $\mathrm{CBD}$ does not bind cannabinoid receptors, this review will not discuss this phytocannabinoid at length. In particular, we focus on the well-established antinociceptive effects of cannabimimetic agents in carrageenan- and lipopolysacharide (LPS)-induced acute inflammatory pain models, as well as in longer-term inflammatory pain models (for example, complete Freund's adjuvant-induced chronic inflammation and collagen-induced arthritis). We also discuss neuropathic pain associated with nerve injury, diabetes, chemotherapeutic agents, and migraine. Table 1 provides an overview of a selected range of rodent assays to assess nociceptive behavior in preclinical inflammatory and neuropathic pain models. Furthermore, we cover the opioid-sparing effects of cannabinoids in terms of cannabinoid effectiveness in reducing opioid doses, thereby reducing side effects of each drug without reducing overall antinociceptive efficacy. Finally, assorted clinical trials testing cannabis in neuropathic pain patients are discussed.

\section{ACUTE AND CHRONIC INFLAMMATORY PAIN}

\section{Anti-Inflammatory Effects: In Vitro Assays}

Pharmacological agents acting on various components of the endocannabinoid system exert anti-inflammatory effects, primarily through suppression of cytokine production, inhibition of cell proliferation, and induction of cell apoptosis (Nagarkatti et al, 2009). The inflammatory response to insult must be tightly regulated in order to minimize damage to healthy tissues. Thus, in addition to proinflammatory cytokines, activated immune cells produce and release antiinflammatory mediators, including interleukin-10 (IL-10), which are regulated by the endocannabinoid system (Klein, 2005). Endocannabinoids mediate inflammation by regulating cytokines at different steps throughout the inflammatory response (Cabral and Griffin-Thomas, 2009). For example, THC and AEA suppress proinflammatory cytokines and enhance anti-inflammatory cytokines in both innate and adaptive immune responses (Cabral and Griffin-Thomas, 2009). AEA inhibits microglial nitric oxide (NO) synthesis through the mitogen-activated protein kinase pathway (Eljaschewitsch et al, 2006) and inhibits tumor necrosis factor $\alpha$ (TNF- $\alpha$ ) activation of the transcription nuclear factor kappa B (Sancho et al, 2003). However, cannabinoids may also increase production of proinflammatory cytokines, depending on the model, dose, and drug probe (Klein, 2005). For example, in vitro studies THC inhibits proinflammatory 


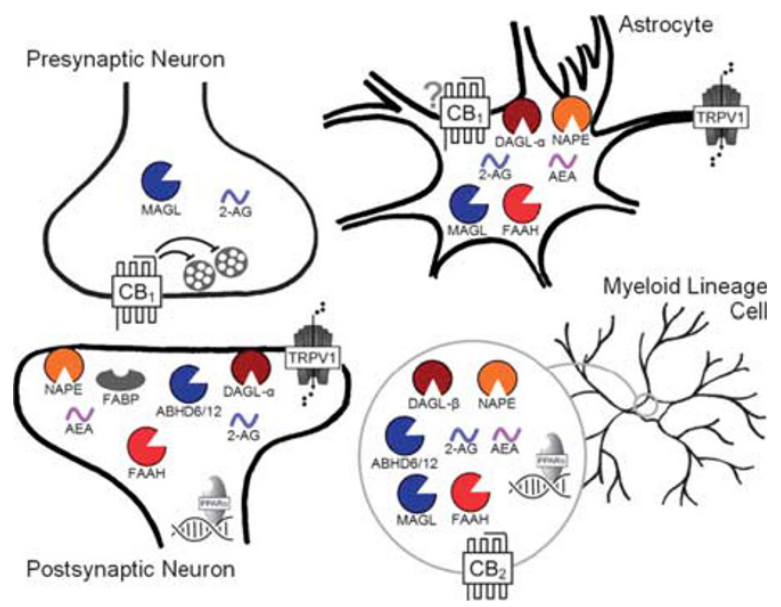

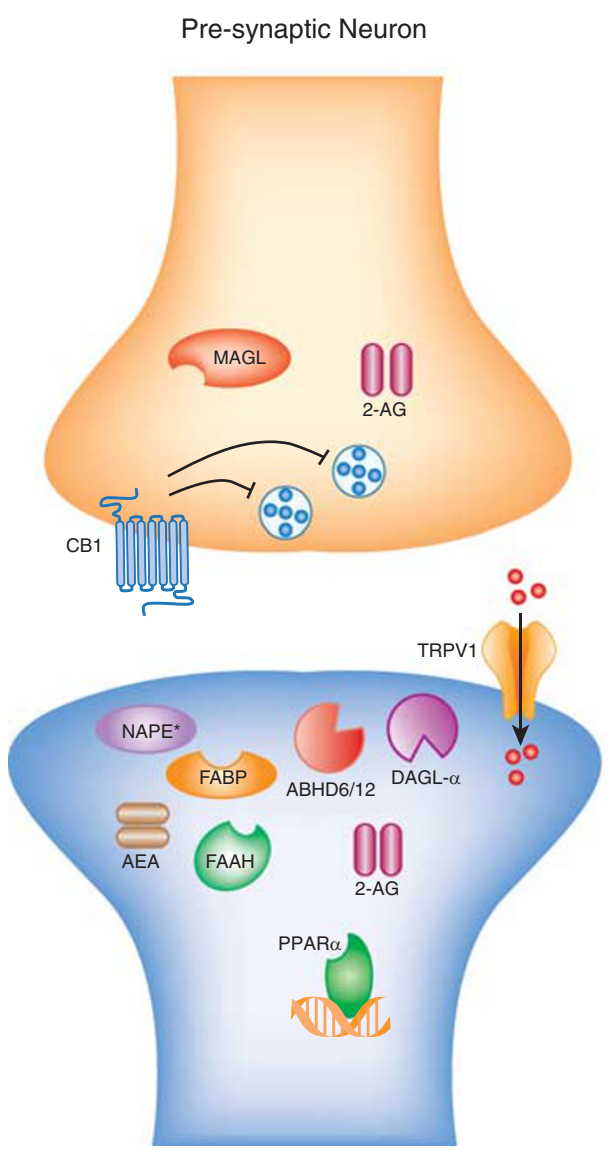

Postsynaptic neuron

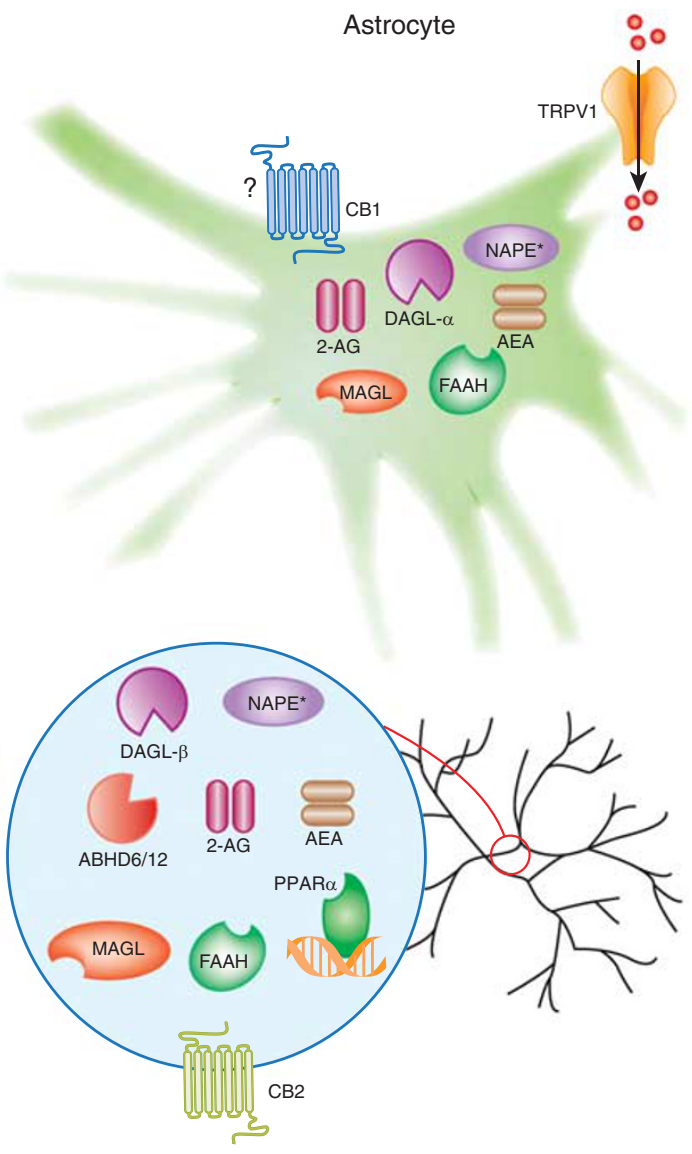

Myeloid lineage cell

Figure 1. Endocannabinoid system localization by CNS cell type. Drugs acting upon cannabinoid receptors and the endocannabinoid-regulating enzymes are determined not only by drug class, efficacy, affinity, and potency, but also by cellular compartmentalization of the drug target. 2-AG, 2arachidonyl glycerol; $\mathrm{ABHD6}, \alpha / \beta$-hydrolase domain-6; $\mathrm{ABHD12}, \alpha / \beta$-hydrolase domain-12; $\mathrm{AEA}$, anandamide; $\mathrm{CB}_{1}$, cannabinoid receptor 1 ; $\mathrm{CB}_{2}$, cannabinoid receptor 2; DAGL- $\alpha$, diacylglycerol lipase- $\alpha$; DAGL- $\beta$, diacylglycerol lipase- $\beta$; FABP, fatty acid binding protein; FAAH, fatty acid amide hydrolase; MAGL, monoacylglycerol lipase; NAPE, $N$-arachidonoyl phosphatidylethanolamine; PPAR- $\alpha$, peroxisome proliferator-activated receptor alpha; TRPV1, transient receptor potential cation channel subfamily $\vee$ member 1. Question marks refer to conflicting evidence to support the targets cellular localization. 


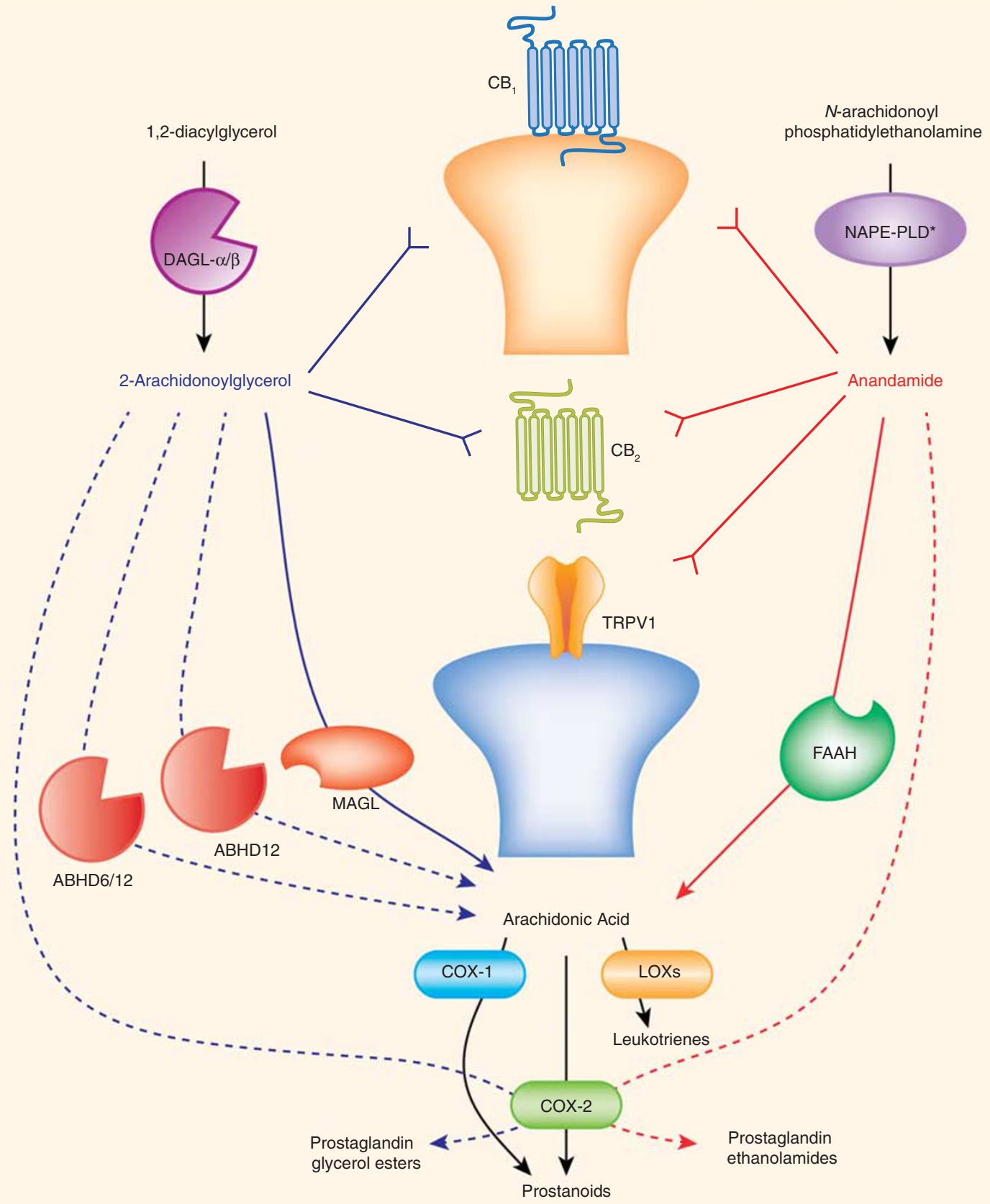

Figure 2. Enzymatic regulation of endocannabinoids and primary targets. Endogenous cannabinoids are enzymatically regulated, produced, and released on demand. Anandamide and 2-AG bind and activate $\mathrm{CB}_{1}$ and $\mathrm{CB}_{2}$ receptors. Anandamide also binds and activates transient receptor potential cation channel subfamily $V$ member 1 (TRPV1). Diacylglycerol lipase (DAGL) alpha and beta synthesize 2-arachidonoylglycerol. $N$-acyl phosphatidylethanolamine-selective phospholipase D (NAPE-PLD*) is one of several enzymes proposed to synthesize anandamide. Monoacylglycerol lipase (MAGL), alpha/beta-hydrolase domain containing (ABHD) 6 and 12 hydrolyze 2-AG to create arachidonic acid. Several enzymes, including cyclooxygenase (COX) 1 and 2 and lipoxygenases (LOXs) convert arachidonic acid into bioactive lipids. COX2 also converts anandamide to prostaglandinethanolamides, and 2-AG to prostaglandin glycerol esters. Thick blue or red lines with arrows represent major degradative pathways for 2-AG and anandamide, respectively. Dashed lines with arrows represent other degradative pathways. Reverse arrows $(Y)$ represent activation of receptor targets of each endocannabinoid.

cytokine synthesis at nanomolar concentrations, but stimulates proinflammatory cytokine synthesis at micromolar concentrations, indicating a biphasic effect (Berdyshev et al, 1997).

Macrophages are the main producers of proinflammatory cytokines, especially during the early stages of the innate immune response. THC and AEA attenuate LPS-stimulated IL-6, and NO release from macrophages in vitro (Chang et al, 2001). Similarly, during the adaptive immune response, $\mathrm{T}$ cells produce cytokines. The endocannabinoid system also modulates inflammation by shifting the balance of $\mathrm{CD} 4^{+}$ 'Helper' T cells through suppression of Th1 proinflammatory 
TABLE 1 Assays to Evaluate Nociceptive Behavior in Rodents

\begin{tabular}{|c|c|c|c|}
\hline Test & Stimulus & Description & Ref \\
\hline Tail flick & Thermal, heat & $\begin{array}{l}\text { The measured parameter is the latency, in seconds, for tail flick reflex following tail } \\
\text { exposure to a heat stimulus. }\end{array}$ & D'Amour and Smith, 194I \\
\hline Hot plate & Thermal, heat & $\begin{array}{l}\text { The measured parameter is usually the latency for paw licking or the first observed } \\
\text { response (ie, jump) when the animal is placed on a hot surface }\left(52 \text { or } 55^{\circ} \mathrm{C}\right) \text {. }\end{array}$ & $\begin{array}{l}\text { O'Callaghan and } \\
\text { Holtzman, } 1975\end{array}$ \\
\hline Acetone test & Thermal, cold & $\begin{array}{l}\text { The measured parameter is usually the number or frequency of brisk foot } \\
\text { withdrawal after applying a drop of acetone to a hind paw. }\end{array}$ & Choi et al, 1994 \\
\hline Von-Frey test & Mechanical & $\begin{array}{l}\text { The measured parameter is usually the withdrawal threshold }(\mathrm{g}) \text { after the randomly } \\
\text { application of a series of calibrated monofilaments on the hind paws for } 3 \mathrm{~s} \text {. }\end{array}$ & Murphy et al, 1999 \\
\hline Randal-Selitto & Mechanical & $\begin{array}{l}\text { The measured parameter is usually the withdrawal threshold }(\mathrm{g}) \text { or vocalization } \\
\text { when the hind paw is placed between a fixed element, such as a surface or a blunt } \\
\text { point, and a mobile blunt point exerting a controlled pressure. }\end{array}$ & Randall and Selitto, 1957 \\
\hline $\begin{array}{l}\text { Conditioned place preference (CPP) } \\
\text { Conditioned place avoidance (CPA) }\end{array}$ & Motivational & $\begin{array}{l}\text { During a preconditioning phase, subjects are placed in a box consisting of a neutral } \\
\text { middle chamber and two chambers on either side (visually, texturally, and olfactory } \\
\text { different). Drug conditioning trials are run with the drug given in one of the two } \\
\text { chambers, which provides the opportunity for the development of an association. } \\
\text { During testing, amount of time spent in the drug-paired chamber indicates a } \\
\text { preference. The measured parameter is the place preference score (PPS). }\end{array}$ & Roux et al, 2003 \\
\hline Intracranial self-administration (ICSS) & Motivational & $\begin{array}{l}\text { Under pain condition, animals are provided with intravenous catheters and allowed } \\
\text { to perform an operant response such as the depression of a lever to self-administer } \\
\text { a drug. This technique has been used extensively to evaluate a drug's propensity for } \\
\text { abuse. }\end{array}$ & $\begin{array}{l}\text { Carlezon and Chartoff, } \\
2007\end{array}$ \\
\hline Nesting test & $\begin{array}{l}\text { Pain-depressed } \\
\text { behavior }\end{array}$ & $\begin{array}{l}\text { The measured parameter is usually the number of area cleared in the animal cage } \\
\text { wherein } 6 \text { nestlet pieces are placed in a period of } 100 \mathrm{~s} \text {. The nesting procedure is } \\
\text { an evaluation of pain-related depressed behavior. }\end{array}$ & Negus et al, 2015 \\
\hline
\end{tabular}

activity and promotion of Th2 anti-inflammatory activity (Yuan et al, 2002). THC decreases Legionella pneumophilainduced production of the proinflammatory cytokines, gamma interferon (IFN- $\gamma$ ) and IL-12, typically released from the Th1 cells, and increase production of the anti-inflammatory cytokine IL-4, released by Th2 cells in mouse splenocytes. Selective antagonists of both the $\mathrm{CB}_{2}$ receptor, SR144528, and $\mathrm{CB}_{1}$ receptor, rimonabant, reverses the suppression of IFN- $\gamma$ and IL-12, indicating that these receptors play necessary roles in the modulation of proinflammatory cytokines (Klein et al, 1985). These results suggest that endogenous cannabinoids inhibit the production of proinflammatory cytokines and increase the production of anti-inflammatory cytokines throughout the inflammatory response.

The endocannabinoid system also modulates the inflammatory response through the suppression of immune cell activation, proliferation and migration, and the activation of immune cell apoptosis. Administration of the cannabinoid receptor agonist, $\mathrm{CP} 55,940$ decreased the migration of rat macrophages through a $\mathrm{CB}_{1}$ and $\mathrm{CB}_{2}$ receptor mechanism in both in vivo and in vitro models (Sacerdote et al, 2000). Furthermore, THC indirectly inhibits the activation of T helper cells by suppressing antigen presentation in macrophages (McCoy et al, 1995).

Cannabinoids also inhibit the cell-specific proliferation of $\mathrm{B}$ and $\mathrm{T}$ cells (Cabral and Griffin-Thomas, 2009; Klein and Cabral, 2006). For example, THC inhibited the proliferation of human $\mathrm{T}$ cells stimulated with antigenprimed dendritic cells (Yuan et al, 2002). Similarly, THC inhibits the proliferation of mouse splenic $\mathrm{T}$ cells stimulated by concanavalin A, and B cells stimulated by LPS (Klein et al, 1985). In addition to inhibiting cell proliferation, THC induces apoptosis of mouse macrophages, $\mathrm{T}$ cells, and $\mathrm{B}$ cells in primary splenic and thymic cultures (McKallip et al, 2002).

Cannabinoids elicit analgesic and immunomodulatory effects in arthritis and other inflammatory diseases. Fibroblast-like synoviocytes (FLS) reside in synovial tissue. FLSs from patients affected by rheumatoid arthritis and osteoarthritis express the $\mathrm{CB}_{1}$ and $\mathrm{CB}_{2}$ receptors (Richardson et al, 2008). Both receptors are expressed on chondrocytes and within the joint cartilage and subchondral bone of patients with osteoarthritis (Dunn et al, 2014, 2016). Within rheumatoid arthritis synovial tissue, $\mathrm{CB}_{2}$ receptors are expressed on macrophages, $\mathrm{CD} 4^{+} \mathrm{T}$ cells, $\mathrm{CD}^{+} \mathrm{T}$ cells, and B cells (Fukuda et al, 2014). Interestingly, AEA and 2AG are present in the synovial fluid of patients affected by both rheumatoid arthritis and osteoarthritis, but not in healthy controls, suggesting an upregulation in response to inflammation and cartilage degradation (Richardson et al, 2008). The presence of cannabinoid receptors in arthritic joints suggests that the endocannabinoid system plays a compensatory role in this disease. However, the lack of highly selective $\mathrm{CB}_{2}$ receptor antibodies limits interpretation of some studies. Thus, the use of stringent negative controls is crucial for the correct detection and quantification of protein targets (Marchalant et al, 2014).

In arthritic synovial tissue, FLSs release matrix metalloproteinases that degrade the cartilage extracellular matrix and pro-inflammatory cytokines (Karouzakis et al, 2006). The release of matrix metalloproteinases and cytokines are 
attenuated by cannabinoids in vitro (Lowin et al, 2015, 2016; Selvi et al, 2008). In FLSs derived from patients with rheumatoid arthritis and osteoarthritis, synthetic cannabinoid receptor agonists (CP55,940, WIN55,212, or Ajulemic acid) or AEA (Lowin et al, 2015) attenuate TNF- $\alpha$ stimulated production of the proinflammatory cytokines IL-6 and IL-8, and matrix degrading enzymes matrix metalloproteinases-1, -3, and -9 (Johnson et al, 2007; Lowin et al, 2015, 2016; Selvi et al, 2008). The selective $\mathrm{CB}_{2}$ receptor agonists HU-308 and JWH133 also reduce IL-6, IL- 8 , and matrix metalloproteinases- 3 from TNF $\alpha$ or IL- $1 \beta$ stimulated rheumatoid arthritis and osteoarthritis FLS (Fukuda et al, 2014; Gui et al, 2014). AEA's attenuation of IL-6 and IL-8 is blocked by the TRPA1 antagonist A967079, but not by $\mathrm{CB}_{1}$ or $\mathrm{CB}_{2}$ receptor antagonists (Lowin et al, 2015), indicating that cannabinoids modulate inflammation through multiple pathways.

In rheumatoid arthritis FLSs stimulated by $\mathrm{TNF} \alpha$, AEA attenuates the phosphorylation of p38 and ERK1/2, but not cJUN, indicating a decrease in mitogen-activated protein kinase activation (Lowin et al, 2015). The selective $\mathrm{CB}_{2}$ receptor agonist HU-308 also inhibited IL-1 $\beta$ stimulated phosphorylation of ERK $1 / 2$ and p38 mitogen-activated protein kinase in FLS from rheumatoid arthritis patients (Gui et al, 2014). These studies suggest that cannabinoids may reduce arthritic inflammation and cartilage degradation by the release of proinflammatory cytokines and matrixdegrading enzymes from FLSs in the synovium through the modulation of ERK1/2 and p38 mitogen-activated protein kinase activity.

Cannabinoids may also reduce cartilage degradation in arthritis through the regulation of chondrocytes. In bovine nasal cartilage stimulated by IL- $1 \beta$, the cannabinoid receptor agonists WIN-55,212-2 and HU-210 prevented the breakdown of proteoglycan and collagen (Mbvundula et al, 2006). WIN-55,212-2 also inhibits the production of $\mathrm{PGE}_{2}$, expression of iNOS, and the activation of nuclear factor kappa B in bovine chondrocytes (Mbvundula et al, 2006). Furthermore, incubation of WIN-55,212-2 alone or in combination with IL- $1 \beta$ decreases the expression of matrix-degrading enzyme matrix metalloproteinases- 3 and -13 , and matrix metalloproteinases tissue inhibitor of metalloproteinase- 1 and -2 in osteoarthritis chondrocytes (Dunn et al, 2014). WIN-55,2122 also attenuates the production of the matrix-degrading enzyme disintegrin and metalloprotease with thrombospondin motifs-4 from osteoarthritis chondrocytes either unstimulated or stimulated with IL-1 $\beta$ (Kong et al, 2016). The attenuation of the metalloprotease with thrombospondin motifs- 4 production is reversed by the selective $\mathrm{CB}_{2}$ receptor antagonist, JTE907, but not the selective $C_{1}$ receptor antagonist, MJ15 indicating that $\mathrm{CB}_{2}$ plays a necessary role in this effect. Taken together, these studies indicate that cannabinoids may reduce cartilage degradation by attenuating the release of matrix-degrading enzymes (that is, matrix metalloproteinases and metalloprotease with thrombospondin motifs) from chondrocytes.

\section{Anti-Inflammatory Effects: In Vivo Assays}

Acute pain models. Cannabinoids have anti-inflammatory properties and also elicit antinociceptive effects by inhibiting neuronal transmission in pain pathways. Cannabinoidinduced antinociception is reported in a variety of preclinical inflammatory pain models (Table 2; also see a review by Guindon and Hohmann, 2009), including intraplantar injection (that is, into the ventral footpad) of the seaweed extract carrageenan, and the Gram-negative bacterial-derived endotoxin lipopolysaccharide (LPS). These non-self inflammogens elicit an innate immune response that results in acute antinociception and localized edema in the affected paw. Several assays are available to test antinociceptive behavior in the animal models of inflammatory pain (Table 1). For example, the synthetic cannabinoid agonist HU-210 restores the carrageenan-induced reduction in weight bearing in rats (Clayton et al, 2002; Elmes et al, 2005; Sofia et al, 1973). Similarly, intraplantar injection of high-dose (that is, $25 \mu \mathrm{g}$ ) LPS induces acute, localized pain and inflammation that is attenuated by synthetic cannabinoid agonists WIN55,212-2 and CP55,940 (Kinsey et al, 2011a; Naidu et al, 2010). These inflammatory pain assays, along with others, have been used to investigate the acute antinociceptive effects of cannabinoid receptor agonists, $\mathrm{CB}_{1}$ receptor-positive allosteric modulators (PAMs), inhibitors of endocannabinoid-regulating enzymes, and inhibitors of endocannabinoid transport.

$\mathrm{CB}_{2}$ receptor-selective agonists represent a promising strategy to bypass the undesirable cognitive and behavioral side effects of mixed $\mathrm{CB}_{1} / \mathrm{CB}_{2}$ receptor agonists. The selective $\mathrm{CB}_{2}$ receptor agonists GW405833 and JWH133 attenuate edema and restore weight bearing in rat paws injected with carrageenan (Clayton et al, 2002; Elmes et al, 2005). The $\mathrm{CB}_{2}$ receptor agonist O-3223 attenuates hyperalgesia and edema induced by intraplantar injection of LPS, and was reversed by the $\mathrm{CB}_{2}$ receptor antagonist, SR144528, but not by rimonabant (Kinsey et al, 2011a).

$\mathrm{CB}_{1}$ receptor PAMs represent another approach to block inflammatory pain without cannabimimetic side effects. For example, the $\mathrm{CB}_{1}$ positive allosteric modulator ZCZ011 increases binding of orthosteric $\mathrm{CB}_{1}$ receptor agonists (Ignatowska-Jankowska et al, 2015b). When administered alone, ZCZ011 attenuates carrageenan-induced mechanical allodynia, but does not elicit anti-edematous effects, mediated by $\mathrm{CB}_{2}$ receptors. The observations that ZCZ011 does not elicit psychomimetic effects in tetrad assay or substitute for cannabinoids in the drug discrimination paradigm, suggesting that this compound has a reduced side effect profile compared with orthosteric $\mathrm{CB}_{1}$ receptor agonists (Ignatowska-Jankowska et al, 2015b).

Inhibiting endocannabinoid catabolic enzymes represents a distinct approach from direct-acting cannabinoid receptor agonists. In general, inhibition of FAAH or MAGL attenuates acute inflammatory pain with reduced cannabimimetic side effects compared with direct-acting $\mathrm{CB}_{1}$ receptor agonists. For example, pharmacological inhibition 
TABLE 2 Antinociceptive Effects of Cannabinoids in Pre-Clinical Models of Acute Inflammatory Pain

\begin{tabular}{|c|c|c|c|c|c|c|c|c|c|c|c|}
\hline Pain model & Type & Treatment & Route & Species & Mechanical & Thermal & $\begin{array}{l}\text { Weight } \\
\text { bearing }\end{array}$ & $\begin{array}{l}\text { Mechanism of } \\
\text { action }\end{array}$ & Edema & $\begin{array}{l}\text { Edema } \\
\text { receptor }\end{array}$ & Citation \\
\hline \multirow[t]{30}{*}{ Carrageenan } & Agonist & THC & p.o. & Rat & N/A & N/A & N/A & N/A & Decrease & N/A & Sofia et al, 1973 \\
\hline & & $\mathrm{H} \cup 210$ & i.p. & Rat & N/A & N/A & yes & $\mathrm{CB}_{1}$ & Decrease & $\mathrm{CB}_{1} \& \mathrm{CB}_{2}$ & Clayton et al, 2002; Elmes et al, 2005 \\
\hline & Phytocannabinoid & THCV & i.p. & Mouse & N/A & Plantar & N/A & Non- $\mathrm{CB}$ & Decrease & $\mathrm{CB}_{2}$ & Bolognini et al, 2010 \\
\hline & $\mathrm{CB}_{1}$ agonist & ACEA & i.pl. & Rat & von Frey & Plantar & N/A & $\mathrm{CB}_{1}$ & $N / A$ & N/A & Gutierrez et al, 2007 \\
\hline & $C B_{1}$ PAM & ZCZOII & i.p. & Mouse & von Frey & N/A & N/A & $\mathrm{CB}_{1}$ & No $\Delta$ & N/A & Ignatowska-Jankowska et al, 2015c \\
\hline & $\mathrm{CB}_{2}$ agonist & GW405833 & i.p. & Rat & N/A & N/A & yes & $\mathrm{CB}_{2}$ & Decrease & $\mathrm{CB}_{2}$ & Clayton et al, 2002 \\
\hline & & JWHI33 & i.p. & Rat & N/A & N/A & yes & $\mathrm{CB}_{2}$ & Decrease & $\mathrm{CB}_{2}$ & Elmes et al, 2005 \\
\hline & & AMI24I & i.p. & Rat & N/A & Plantar & N/A & $\mathrm{CB}_{2}$ & No $\Delta$ & N/A & $\begin{array}{l}\text { Bingham et al, 2007; Nackley et al, } \\
\text { 2003; Quartilho et al, } 2003\end{array}$ \\
\hline & & AMI24I & i.pl. & Rat & von Frey & Plantar & N/A & $\mathrm{CB}_{2}$ & N/A & N/A & $\begin{array}{l}\text { Quartilho et al, } 2003 \text { (plantar only); } \\
\text { Gutierrez et al, } 2007 \text {; Nackley et al, } \\
2003 \text { (von Frey and plantar) }\end{array}$ \\
\hline & $\mathrm{CB}_{2}$ inverse agonist & JTE-907 & & Mouse & N/A & N/A & N/A & N/A & Decrease & N/A & Iwamura et al, 200| \\
\hline & $\mathrm{CB}_{2}$ agonist $+\mathrm{CB}_{1}$ agonist & AMI24I + ACEA & i.pl. & Rat & N/A & Plantar & N/A & N/A & Decrease & $\mathrm{CB}_{2}$ & Gutierrez et al, 2007 \\
\hline & FAAH inhibition & FAAH KO & N/A & Mouse & N/A & Plantar & N/A & $\mathrm{CB}_{2}$ & Decrease & $\mathrm{CB}_{2}$ & Lichtman et al, 2004; Wise et al, 2008 \\
\hline & & URB597 & i.p. & Mouse & N/A & No & N/A & $N / A$ & Decrease & $\mathrm{CB}_{2}$ & $\begin{array}{l}\text { Holt et al, } 2005 \text { (edema only); Costa } \\
\text { et al, } 2010\end{array}$ \\
\hline & & URB597 & i.pl. & Rat & N/A & N/A & yes & PPAR- $\alpha$ & No $\Delta$ & N/A & Jhaveri et al, 2008 \\
\hline & & URB937 & i.p. & Mouse & $\begin{array}{l}\text { von Frey \& } \\
\text { pressure }\end{array}$ & Plantar & N/A & $\mathrm{CB}_{1}$ & Decrease & $C B_{1} \& C_{2}$ & Clapper et al, 2010 \\
\hline & & JNJ-1661010 & & Rat & N/A & Plantar & N/A & N/A & N/A & N/A & Karbarz et al, 2009 \\
\hline & & PF-3845 & i.p. & Mouse & von Frey & N/A & N/A & N/A & Decrease & N/A & Ghosh et al, 2013 \\
\hline & MAGL inhibition & URB602 & i.p. & Mouse & $N / A$ & Plantar & N/A & $\mathrm{CB}_{2}$ & Decrease & $\mathrm{CB}_{2}$ & Comelli et al, 2007 \\
\hline & & JZLI84 & i.p. & Mouse & von Frey & N/A & N/A & $C B_{1} \& C_{2}$ & Decrease & $\mathrm{CB}_{2}$ & Ghosh et al, 2013 \\
\hline & & KMLI29 & i.p. & Mouse & von Frey & N/A & N/A & $\mathrm{CB}_{1} \& \mathrm{CB}_{2}$ & Decrease & $\mathrm{CB}_{2}$ & Ignatowska-Jankowska et al, 2014 \\
\hline & FABP & SBFI26 & i.p. & Mouse & $N / A$ & Plantar & N/A & N/A & Decrease & N/A & Kaczocha et al, 2014 \\
\hline & & SBFI50 & i.p. & Mouse & N/A & Plantar & N/A & N/A & Decrease & N/A & Kaczocha et al, 2014 \\
\hline & & $\mathrm{FABP} 5 / 7 \mathrm{KO}$ & N/A & Mouse & N/A & Plantar & N/A & PPAR- $\alpha$ \& TRPVI & Decrease & $N / A$ & Kaczocha et al, 2015 \\
\hline & FAAH inhibition + NSAID & URB937 + Indomethacin & p.o. & Mouse & Pressure & Plantar & N/A & N/A & Decrease & $N / A$ & Sasso et al, 2012 \\
\hline & & PF-3845 + Diclofenac & i.p. & Mouse & von Frey & N/A & N/A & $\mathrm{CB}_{1} \& \mathrm{CB}_{2}$ & $N / A$ & $N / A$ & Grim et al, 2014 \\
\hline & FAAH \& MAGL inhibition & PF-3845 + JZLI 84 & i.p. & Mouse & von Frey & N/A & N/A & $\mathrm{CB}_{1} \& \mathrm{CB}_{2}$ & Decrease & $\mathrm{CB}_{2}$ & Ghosh et al, 2015 \\
\hline & & SA-57 & i.p. & Mouse & von Frey & N/A & N/A & $\mathrm{CB}_{1} \& \mathrm{CB}_{2}$ & Decrease & $\mathrm{CB}_{2}$ & Wilkerson et al, 2017 \\
\hline & $\begin{array}{l}\text { FAAH inhibition + TRPVI } \\
\text { antagonism }\end{array}$ & AA-5-HT & i.p. & Mouse & Randall-Stiletto & Plantar & N/A & $C B_{1} \&$ TRPVI & Decrease & TRPVI & Costa et al, 2010 \\
\hline & $\begin{array}{l}\text { FAAH inhibition + TRPVI } \\
\text { antagonism }\end{array}$ & AA-5-HT & i.pl. & Mouse & no & No & N/A & $N / A$ & $N / A$ & $N / A$ & Costa et al, 2010 \\
\hline & FAAH \& sHE inhibition & URB937 + TPPU & p.o. & Mouse & pressure & Plantar & N/A & N/A & Decrease & N/A & Sasso et al, 2015 \\
\hline \multirow[t]{3}{*}{ LPS (high dose) } & Agonist & WIN55212-2 & i.p. & Mouse & N/A & $\mathrm{HP}$ & N/A & N/A & Decrease & $N / A$ & Naidu et al, 2010 \\
\hline & & CP55,940 & i.p. & Mouse & N/A & $\mathrm{HP}$ & N/A & $C B_{1} \& C_{2}$ & Decrease & $\mathrm{CB}_{2}$ & Kinsey et al, $201 \mathrm{la}$ \\
\hline & $\mathrm{CB}_{2}$ agonist & $0-3223$ & i.p. & Mouse & N/A & $\mathrm{HP}$ & N/A & $\mathrm{CB}_{2}$ & Decrease & $\mathrm{CB}_{2}$ & Kinsey et al, $201 \mathrm{la}$ \\
\hline
\end{tabular}




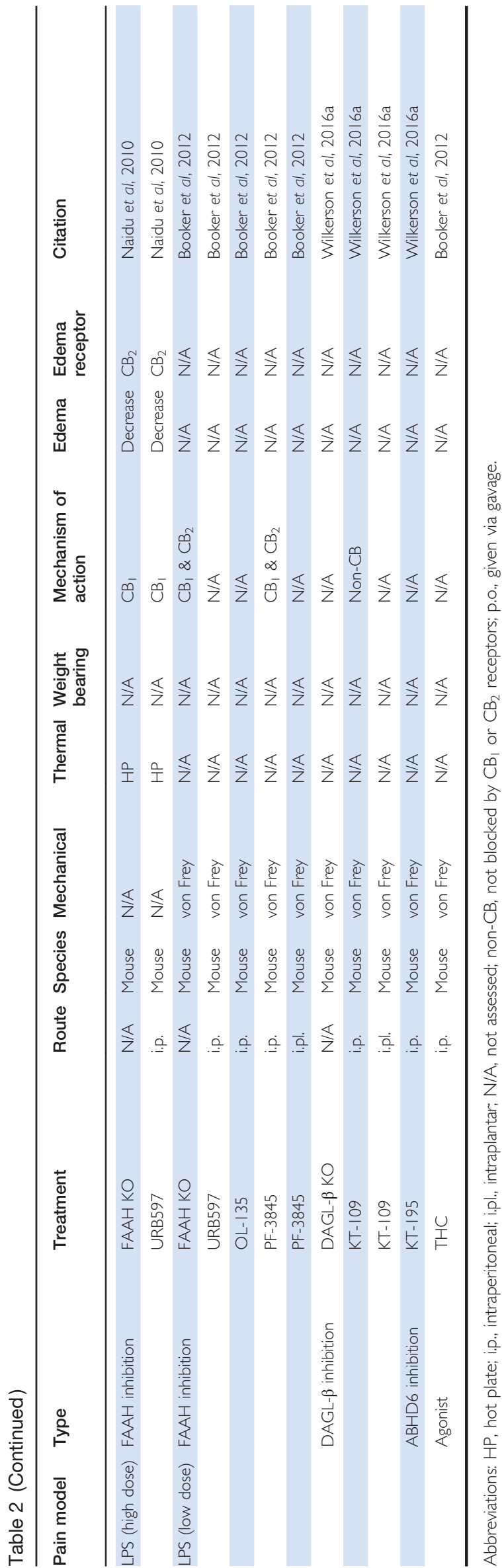

or genetic deletion of FAAH attenuates carrageenan-induced inflammation as well as mechanical allodynia and thermal hyperalgesia (increased sensitivity to a noxious heat stimuli) (Ghosh et al, 2013; Karbarz et al, 2009; Lichtman et al, 2004). FAAH inhibitors also attenuate carrageenaninduced edema, an effect that is mediated through the $\mathrm{CB}_{2}$ receptor (Holt et al, 2005; Lichtman et al, 2004). The FAAH inhibitor URB597, or genetic deletion of FAAH, also attenuates LPS-induced hyperalgesia and edema (Naidu et al, 2010). The anti-hyperalgesic effect of FAAH inhibition in the LPS model was reversed by $\mathrm{CB}_{1}$ receptor antagonism, whereas the anti-edematous effect was reversed by $\mathrm{CB}_{2}$ antagonism (Naidu et al, 2010). Similarly, the peripherally restricted FAAH inhibitor URB937 attenuates carrageenaninduced allodynia and hyperalgesia through a $\mathrm{CB}_{1}$ mechanism of action. However, unlike brain-permeating FAAH inhibitors, the anti-edematous effects of URB937 are mediated by both $\mathrm{CB}_{1}$ and $\mathrm{CB}_{2}$ receptors (Clapper et al, 2010).

Similarly, inhibition of MAGL, the primary catabolic enzyme of 2-AG (Blankman et al, 2007), attenuates carrageenan-induced, acute paw edema and inflammatory pain (Comelli et al, 2007; Ghosh et al, 2013; IgnatowskaJankowska et al, 2014). The selective MAGL inhibitors JZL184 and KML129 attenuate carrageenan-induced mechanical allodynia through $\mathrm{CB}_{1}$ and $\mathrm{CB}_{2}$ receptor-dependent mechanisms, but only $\mathrm{CB}_{2}$ receptors mediate the antiedematous effects of these inhibitors (Ghosh et al, 2013; Ignatowska-Jankowska et al, 2014). Combining a high dose of the FAAH inhibitor, PF-3845 with a low dose of the MAGL inhibitor, JZL184, attenuates carrageenan induced mechanical allodynia and paw edema in mice to a greater degree than either drug alone (Ghosh et al, 2015). Similarly, the dual FAAH/MAGL inhibitor SA-57 attenuates allodynia and edema induced by intraplantar carrageenan (Wilkerson et al, 2017). The anti-allodynic effects of combined FAAH/MAGL inhibition are reversed by either $\mathrm{CB}_{1}$ or $\mathrm{CB}_{2}$ receptor antagonists, whereas only a $\mathrm{CB}_{2}$ receptor antagonist reverses the anti-edematous effects of dual FAAH/MAGL inhibition.

FAAH inhibition has also been combined with other, noncannabinoid analgesics to attenuate edema and pain in the carrageenan model. For example, AA-5-HT, a dual FAAH inhibitor/transient receptor potential cation channel subfamily V member 1 (TRPV1) antagonist, attenuates thermal and mechanical hyperalgesia, as well as edema produced by an intraplantar injection of carrageenan (Costa et al, 2010). Epoxidized fatty acids exert anti-inflammatory and antinociceptive effects, and are metabolized by the enzyme soluble epoxide hydrolase. Combined administration of the peripherally-restricted FAAH inhibitor, URB937, and the epoxide hydrolase inhibitor, TPPU, attenuates carrageenaninduced mechanical and thermal hyperalgesia, as well as, paw edema, in a synergistic manner (Sasso et al, 2015). Similarly, dual administration of URB937 and the nonsteroidal anti-inflammatory drug (NSAID) indomethacin synergistically attenuates hyperalgesia, allodynia, and edema 
induced by intraplantar carrageenan injection (Sasso et al, 2012). Mechanical allodynia induced by carrageenan injection is also reduced by coadministration of the FAAH inhibitor PF-3845 and the NSAID diclofenac (Grim et al, 2014). The anti-allodynic effect is blocked by SR144528 or rimonabant, indicating that both cannabinoid receptors mediate this antinociceptive effect (Grim et al, 2014).

Fatty acid-binding proteins (FABPs) are proposed to transport endocannabinoids intracellularly, from the cell membrane to the endoplasmic reticulum for hydrolysis (Kaczocha et al, 2009). The FABP inhibitors SBFI26 and SBFI50 attenuate carrageenan-induced acute paw edema and thermal hyperalgesia (Kaczocha et al, 2014). Similarly, genetic deletion of FABP5 and FABP7 reduces thermal hyperalgesia and edema induced by carrageenan injection (Kaczocha et al, 2015). PPAR- $\alpha$ and TRPV1 receptors mediate the anti-hyperalgesic phenotypes of FABP5 $(-/-)$ mice and FABP7 $(-/-)$ mice. These data suggest that preventing endocannabinoid degradation through inhibition of either their catabolic enzymes or FABPs attenuates acute inflammatory pain.

Localized administration of low dose (ie, $2.5 \mu \mathrm{g}$ ) LPS evokes tactile allodynia that is attenuated by FAAH inhibition without inducing paw edema (Booker et al, 2012). Genetic deletion of FAAH also reduces mechanical allodynia induced by low-dose LPS, but this anti-allodynia is absent in mice expressing FAAH only in nervous tissue (Booker et al, 2012) and is mediated by both $\mathrm{CB}_{1}$ and $\mathrm{CB}_{2}$ receptors. Intraplantar administration of PF-3845 also attenuates LPS-induced allodynia (Booker et al, 2012). However, inhibition of ABHD6, an enzyme that plays a minor role in 2-AG degradation (Blankman et al, 2007), does not affect LPSinduced allodynia (Wilkerson et al, 2016a).

Blockade of the 2-AG biosynthetic enzyme DAGL- $\beta$ also produces antinociception in the LPS model of inflammatory pain. Systemic or localized administration of the DAGL- $\beta$ inhibitor KT-109 reversed mechanical allodynia induced by intraplantar injection of low-dose LPS (Wilkerson et al, 2016a). Moreover, DAGL- $\beta(-/-)$ mice displayed an antinociceptive phenotype in this model. The antinociceptive effects following pharmacological inhibition or genetic deletion of DAGL- $\beta$ are possibly the result of reduced production of proinflammatory metabolites of arachidonic acid in macrophages. Specifically, DAGL- $\beta$ is highly expressed in macrophages, and its blockade leads to reduced levels of 2-AG, arachidonic acid, and a variety of proinflammatory arachidonic acid metabolites and proinflammatory cytokines in these cells (Hsu et al, 2012). Importantly, DAGL- $\beta$ inhibition also blocks the LPS-induced production of proinflammatory mediators (Hsu et al, 2012). Thus, increasing 2-AG levels via MAGL inhibition reduces LPSinduced nociception through a cannabinoid receptor mechanism of action, while decreasing 2-AG levels in peripheral tissue (possibly in macrophages) by inhibiting DAGL- $\beta$ reduces LPS-induced nociception by dampening the innate immune response.
Chronic pain models. Unlike carrageenan or LPS that only induce inflammatory pain for a period of hours to a few days, other inflammatory pain models elicit nociceptive behavior that may persist for weeks. Several wellcharacterized long-term inflammatory pain models include the complete Freund's adjuvant (CFA) model, which induces nociception and paw swelling, osteroarthritis, produced by intra-articular injection of monosodium iodoacetate (MIA), and the collagen-induced arthritis (CIA) model, a wellcharacterized mouse model of inflammatory arthritis. These models of chronic inflammatory pain lead to a variety of changes in the endocannabinoid system. Moreover, a wide range of cannabimimetic agents produce antinociception in CFA and CIA inflammatory pain models (Table 3), as well as osteroarthritis models (Table 4).

CFA administration into a ventral footpad leads to upregulation of $\mathrm{CB}_{2}$ receptors, but not $\mathrm{CB}_{2}$ receptor mRNA in dorsal root ganglia or ipsilateral paw tissue of rats, suggesting that these receptors play an integral role in the endocannabinoid modulation of chronic inflammatory pain (Hsieh et al, 2011). Acute administration of $\mathrm{CB}_{2}$ receptor agonists reduces CFA-induced mechanical and thermal hyperalgesia (Hsieh et al, 2011; Valenzano et al, 2005; Yao et al, 2008, 2009). Furthermore, intraplantar administration of the $\mathrm{CB}_{2}$ receptor agonist JWH015 reduces allodynia and hyperalgesia induced by CFA injection (Negrete et al, 2011). Unexpectedly, the antinociceptive effects of this drug are mediated by $\mathrm{CB}_{2}$ receptors and $\mu$ opioid receptors (MORs). The observation that CFA leads to increased expression of these receptors in the paw and dorsal root ganglia may account for the recruitment of MORs (Negrete et al, 2011). Systemic or intrathecal administration of NMP-181, which acts as a $\mathrm{CB}_{2}$ receptor agonist and T-type channel inhibitor, also attenuates CFA-induced mechanical hyperalgesia (Gadotti et al, 2013). In another study, the $\mathrm{CB}_{2}$ receptor agonist GW405833 was reported to produce antinoiceptive effects through $\mathrm{CB}_{1}$ receptor mechanism of action, while $\mathrm{CB}_{2}$ receptors were dispensible ( $\mathrm{Li}$ et al, 2017). Selective $\mathrm{CB}_{2}$ receptor agonists often possess low $\mathrm{CB}_{1}$ receptor affinity, and when administered in vivo may activate both receptors, particularly when administered at high doses. Thus, studies employing $\mathrm{CB}_{2}$ receptor-selective agonists need to apply caution by testing whether $\mathrm{CB}_{1}$ receptors contribute to any observed effects.

Although CFA leads to an upregulation of $\mathrm{CB}_{2}$ receptors, $\mathrm{CB}_{1}$ receptor stimulation also attenuates chronic inflammatory pain. Localized administration of the $\mathrm{CB}_{1}$ receptor agonist ACPA attenuates CFA-induced mechanical hyperalgesia (Auh et al, 2016). Combination of ACPA and the MOR agonist DAMGO reduces CFA-induced hyperalgesia. However, isobolographic analyses revealed that the interaction is infra-additive, indicating that the combination is less effective than either drug by itself (Auh et al, 2016).

In agreement with studies employing acute inflammatory pain models, inhibition of endocannabinoid catabolic enzymes also reduces chronic inflammatory pain. For example, FAAH inhibition attenuates mechanically-induced 
TABLE 3 Antinociceptive Effects of Cannabinoids in Pre-Clinical Models of Chronic Inflammatory Pain

\begin{tabular}{|c|c|c|c|c|c|c|c|c|c|c|c|c|}
\hline $\begin{array}{l}\text { Pain } \\
\text { model }\end{array}$ & Type & Treatment & Route & Species & Mechanical & Thermal & $\begin{array}{l}\text { Pain } \\
\text { receptor }\end{array}$ & Inflammation & $\begin{array}{l}\text { Mechanism of } \\
\text { action }\end{array}$ & $\begin{array}{l}\text { Joint } \\
\text { damage }\end{array}$ & $\begin{array}{l}\text { Joint } \\
\text { receptor }\end{array}$ & References \\
\hline \multirow[t]{8}{*}{$\mathrm{ClA}$} & CBD derivatives & $\mathrm{CBD}$ & i.p. \& p.o. & Mouse & $\mathrm{N} / \mathrm{A}$ & $N / A$ & N/A & Decrease & N/A & Decrease & N/A & Malfait et al, 2000 \\
\hline & & HU320 & i.p. & Mouse & $N / A$ & $N / A$ & N/A & Decrease & $\mathrm{N} / \mathrm{A}$ & Decrease & N/A & Sumariwalla et al, 2004 \\
\hline & & HU-444 & i.p. \& p.o. & Mouse & N/A & $N / A$ & $N / A$ & Decrease & N/A & Decrease & N/A & Haj et al, 2015 \\
\hline & $\mathrm{CB}_{2}$ agonist & JWHI33 & i.p. & Mouse & N/A & N/A & N/A & Decrease & N/A & Decrease & N/A & Fukuda et al, 2014 \\
\hline & & HU-308 & i.p. & Mouse & $N / A$ & $N / A$ & $N / A$ & Decrease & N/A & Decrease & N/A & Gui et al, 2015 \\
\hline & FAAH inhibition & FAAH KO & $N / A$ & Mouse & $N / A$ & $\begin{array}{l}\text { HP \& Tail } \\
\text { immersion }\end{array}$ & N/A & Decrease & $\mathrm{CB}_{2}$ & Decrease & $\mathrm{CB}_{2}$ & Kinsey et al, $201 \mathrm{lb}$ \\
\hline & & URB597 & i.p. & Mouse & $\mathrm{N} / \mathrm{A}$ & $\begin{array}{l}\text { HP \& Tail } \\
\text { immersion }\end{array}$ & $\mathrm{CB}_{1}$ & Decrease & N/A & Decrease & N/A & Kinsey et al, $201 \mathrm{lb}$ \\
\hline & & JNJ1661010 & i.p. & Mouse & $\mathrm{N} / \mathrm{A}$ & $N / A$ & N/A & Decrease & N/A & $\mathrm{N} / \mathrm{A}$ & N/A & Lowin et al, 2015 \\
\hline \multirow[t]{3}{*}{ AIA } & Agonist & $\mathrm{THC}$ & $\begin{array}{l}\text { i.p. \& p.o. } \\
\text { (swelling) }\end{array}$ & Rat & Pressure & N/A & $\begin{array}{l}\mathrm{CB}_{1}, \mathrm{CB}_{2}, \& \\
\text { opioid }\end{array}$ & Decrease & $N / A$ & $\mathrm{~N} / \mathrm{A}$ & N/A & $\begin{array}{l}\text { Sofia et al, } 1973 \text { (swelling); } \\
\text { Cox et al, 2007; Cox and } \\
\text { Welch, 2004; Smith et al, } \\
1998\end{array}$ \\
\hline & & Ajulemic acid & p.o. & Rat & $\mathrm{N} / \mathrm{A}$ & $N / A$ & N/A & Decrease & $\mathrm{N} / \mathrm{A}$ & Decrease & N/A & Zurier et al, 1998 \\
\hline & & AEA & i.p. & Rat & Pressure & $N / A$ & Non- $\mathrm{CB}_{1}$ & N/A & N/A & N/A & N/A & Smith et al, 1998 \\
\hline \multirow[t]{17}{*}{ CFA } & Agonist & WIN552I2-2 & s.c. & Mouse & von Frey & Plantar & $C B_{1} \& C B_{2}$ & N/A & $N / A$ & N/A & N/A & Anderson et al, 2014 \\
\hline & & $\mathrm{HU}-210$ & i.p. & Rat & von Frey & Plantar & N/A & N/A & N/A & N/A & N/A & Jayamanne et al, 2006 \\
\hline & $\mathrm{CB}_{1}$ agonist & ACPA & i.pl. & Rat & Randall-Selitto & $N / A$ & $N / A$ & N/A & N/A & $\mathrm{N} / \mathrm{A}$ & N/A & Auh et al, 2016 \\
\hline & $\mathrm{CB}_{2}$ agonist & A-796260 & i.p. & Rat & N/A & Plantar & $\mathrm{CB}_{2}$ & N/A & N/A & N/A & N/A & Yao et al, 2008 \\
\hline & & GW405833 & i.p. & Mouse \& Rat & $\begin{array}{l}\text { von Frey }(M) \& \\
\text { pressure }(R)\end{array}$ & $N / A$ & $\mathrm{CB}_{2}$ & N/A & $\mathrm{CB}_{1}$ & $\mathrm{~N} / \mathrm{A}$ & N/A & $\begin{array}{l}\text { Li et al, 20 I7; Valenzano } \\
\text { et al, 2005; Whiteside et al, } \\
2005\end{array}$ \\
\hline & & A-836339 & i.p. & Rat & $\mathrm{N} / \mathrm{A}$ & Plantar & $\mathrm{CB}_{2}$ & N/A & N/A & N/A & N/A & Hsieh et al, 201I \\
\hline & & JWHOI5 & i.pl. & Mouse & von Frey & Plantar & $\mathrm{CB}_{2} \& \mathrm{MOR}$ & N/A & N/A & N/A & N/A & Negrete et al, 2011 \\
\hline & & AMI24I & i.p. & Rat & $\mathrm{N} / \mathrm{A}$ & Plantar & N/A & N/A & N/A & N/A & N/A & Hsieh et al, 201I \\
\hline & FAAH inhibition & URB597 & i.p. & Rat & von Frey & Plantar & $\mathrm{CB}_{1} \& \mathrm{CB}_{2}$ & N/A & N/A & N/A & N/A & Jayamanne et al, 2006 \\
\hline & & PF-3845 & p.o. & Rat & von Frey & N/A & $\mathrm{CB}_{1} \& \mathrm{CB}_{2}$ & N/A & N/A & $\mathrm{N} / \mathrm{A}$ & N/A & Ahn et al, 2009 \\
\hline & & PF-04457845 & p.o. & Rat & von Frey & $N / A$ & $\mathrm{CB}_{1} \& \mathrm{CB}_{2}$ & N/A & N/A & N/A & N/A & Ahn et al, 2011 \\
\hline & & URB-937 & p.o. & Mouse & Pressure & Plantar & N/A & N/A & N/A & $\mathrm{N} / \mathrm{A}$ & N/A & Sasso et al, 2012 \\
\hline & Multiple targets & AM404 & s.c. & Rat & Randall-Selitto & Plantar & $C B_{1}$ & N/A & N/A & N/A & N/A & La Rana et al, 2008 \\
\hline & $\begin{array}{l}\mathrm{CB}_{1}+\mathrm{MOR} \\
\text { agonist }\end{array}$ & $\begin{array}{l}\text { ACPA + } \\
\text { DAMGO }\end{array}$ & i.pl. & Rat & $\begin{array}{l}\text { Randall-Selitto; } \\
\text { attenuate by } \\
\text { antagonistic }\end{array}$ & $N / A$ & $N / A$ & N/A & N/A & $\mathrm{N} / \mathrm{A}$ & N/A & Auh et al, 2016 \\
\hline & $\begin{array}{l}\mathrm{CB}_{2} \text { agonist }+ \\
\text { T-type channel } \\
\text { inhibition }\end{array}$ & NMP-|8| & i.p. \& i.t. & Mouse & DPA & $N / A$ & N/A & N/A & $N / A$ & N/A & N/A & Gadotti et al, 2013 \\
\hline & $\begin{array}{l}\mathrm{CB}_{2} \text { agonist }+ \\
\text { T-type channel } \\
\text { inhibition }\end{array}$ & NMP-|8| & i.p. \& i.t. & Mouse & DPA & $N / A$ & $N / A$ & N/A & $N / A$ & $\mathrm{~N} / \mathrm{A}$ & N/A & Gadotti et al, 2013 \\
\hline & $\begin{array}{l}\text { FAAH \& MAGL } \\
\text { inhibition }\end{array}$ & JZL195 & s.c. & Mouse & von Frey & Plantar & $C B_{1} \& C B_{2}$ & N/A & N/A & $\mathrm{N} / \mathrm{A}$ & N/A & Anderson et al, 2014 \\
\hline
\end{tabular}

Abbreviations: AAIA, adjuvant-induced arthritis; HP, hot plate; i.p., intraperitoneal; i.pl., intraplantar; i.t., intrathecal; p.o., given via gavage; MOR, $\mu$-opioid receptor, N/A, not assessed; s.c., subcutaneous. 
pain in the CFA model of inflammatory pain (Ahn et al, 2009, 2011; Jayamanne et al, 2006; Sasso et al, 2012). These anti-allodynic effects are mediated by both the $\mathrm{CB}_{1}$ and $\mathrm{CB}_{2}$ receptors. The dual FAAH-MAGL inhibitor JZL195 reduces mechanical allodynia and thermal hyperalgesia induced by CFA injection (Anderson et al, 2014). The $\mathrm{CB}_{1}$ receptor antagonist AM251 fully reverses these antinociceptive effects, while the $\mathrm{CB}_{2}$ receptor antagonist AM630 partially reverses these effects (Anderson et al, 2014).

Administration of $\mathrm{CBD}$, or its synthetic analogs, attenuates clinical signs of arthritis and joint damage, while having an immunosuppressant effect in CIA (Haj et al, 2015; Malfait et al, 2000; Sumariwalla et al, 2004). The selective $\mathrm{CB}_{2}$ receptor agonists JWH133 and HU-308 attenuated paw swelling, cartilage degradation, and bone erosion in mice subjected to CIA (Fukuda et al, 2014; Gui et al, 2015). The antiinflammatory and analgesic effects of FAAH inhibition have also been investigated in the CIA model. Wild-type mice treated with URB597 or FAAH $(-/-)$ mice subjected to CIA show reduced thermal hyperalgesia in the hot plate and tail immersion tests. Furthermore, chronic FAAH inhibition reduces CIA-induced paw swelling (Kinsey et al, 2011b; Lowin et al, 2015) and joint destruction (Kinsey et al, 2011b).

Osteoarthritis is a highly prevalent type of arthritis characterized by synovitis, and degeneration of both articular cartilage and subchondral bone in the joints of the hands, knees, hips, and spine (Goldring and Goldring, 2007). MIA induces chondrocyte death, cartilage degradation, and chronic nociception (Burston et al, 2013). This nociception and joint damage occur ipsilateral, but not contralateral, to the injection site. Administration of MIA into the knee joint leads to upregulation of $\mathrm{CB}_{2}$ and $\mathrm{CB}_{1}$ receptor mRNA in the ipsilateral spinal cord of rats, suggesting that these receptors undergo compensatory changes in this osteoarthritis model, and may represent potential targets for novel osteoarthritis treatments (Burston et al, 2013; Malek et al, 2015).

After MIA administration, $\mathrm{CB}_{2}(-/-)$ mice show augmented mechanical allodynia compared with wild-type littermates (La Porta et al, 2013). Interestingly, $\mathrm{CB}_{2}(-/-)$ mice also display allodynia in the contralateral paw after MIA. This bilateral augmented allodynic response has also been reported to occur in $\mathrm{CB}_{2}(-/-)$ mice subjected to sciatic nerve injury, indicating the mirrored response is not MIA model specific (Racz et al, 2008). By comparison, $\mathrm{CB}_{1}$ $(-/-)$ mice do not differ in allodynic response on the ipsilateral or contralateral paw after MIA, supporting the role of $\mathrm{CB}_{2}$ in the development of allodynia in osteoarthritis ( $\mathrm{La}$ Porta et al, 2013).

Mice overexpressing the $\mathrm{CB}_{2}$ receptor $\left(\mathrm{CB}_{2} \mathrm{xP}\right)$ display an attenuated MIA-induced mechanical allodynic phenotype (La Porta et al, 2013). Furthermore, the $\mathrm{CB}_{2}$ receptor agonist JWH133 attenuates MIA-induced allodynia and restores weight bearing on the arthritic joint (Burston et al, 2013). Intrathecal injection of JWH133 also attenuates the firing of wide dynamic range neurons after MIA injection, indicating $\mathrm{CB}_{2}$ receptor activation in the spinal cord may attenuate MIA-induced allodynia (Burston et al, 2013). 
Osteoarthritis can also be modeled in mice by destabilization of the medial meniscus by surgically sectioning a ligament in the joint. The $\mathrm{CB}_{2}$ receptor agonist HU308 reduced joint damage in the DMM osteoarthritis model, whereas $\mathrm{CB}_{2}(-/-)$ mice developed more joint damage than wildtype mice (Sophocleous et al, 2015). By contrast, $\mathrm{CB}_{2}(-/-$ ) mice, $\mathrm{CB}_{2} \mathrm{xP}$ mice, and $\mathrm{CB}_{1}(-/-)$ mice subjected to MIAinduced arthritis do no differ from wild-type mice in the amount of joint damage (La Porta et al, 2013). These conflicting results may be attributed to variations in the progression of joint destruction in the different models.

Inhibition of the major endocannabinoid catabolic enzymes also attenuates pain in a rodent model of osteoarthritis. The FAAH inhibitor URB597 reduces MIA-induced mechanical hyperalgesia and restores weight bearing on the arthritic limb (Malek et al, 2015; Schuelert et al, 2011). OMDM-198, a combined FAAH inhibitor-TRPV1 antagonist, attenuates mechanical hyperalgesia elicited by MIA injection (Malek et al, 2015). Furthermore, MIA administration leads to upregulation of FAAH and TRPV1 mRNA in the ipsilateral spinal cord (Malek et al, 2015). The MAGL inhibitor MJN110 also attenuates mechanical allodynia and restores MIA limb weight bearing. The anti-allodynic effects of MJN110 were mediated by a $\mathrm{CB}_{2}$ receptor mechanism of action, while $\mathrm{CB}_{1}$ receptors did not play a necessary role in this effect. However, weight bearing was only partially blocked by the $\mathrm{CB}_{2}$ receptor antagonist, SR144528, but fully blocked by rimonabant, indicating a difference in receptor mechanism (Burston et al, 2016).

Two noteworthy caveats to preclinical inflammatory pain models are that anti-inflammatory treatments, including manipulation of the endocannabinoid system, are often as follows: (1) administered prior to the induction of inflammation and thus block development of inflammation; and (2) administered repeatedly for a few days (ie, subchronically). In addition, acute manipulation of the endocannabinoid system typically reduces pain measures via $C_{1}$ receptor. These experimental limitations must be considered when translating results from preclinical research to the clinic.

\section{NEUROPATHIC PAIN}

Neuropathic pain is a severe chronic, debilitating condition associated with nerve injury (for example, structural, nutritional, toxic, infectious, or autoimmune damage) that also develops following lesions to the CNS or PNS insult. Neuropathic pain often manifests as a spontaneous burning, tingling, or shooting sensation, which can be amplified by noxious (pressure, heat, and cold), and otherwise innocuous (touch and warm or cool temperatures) mechanical and thermal stimuli (Jensen and Finnerup, 2014). Neuropathic pain pathophysiology is complex and includes functional alterations of the CNS and PNS (Cohen and Mao, 2014) in addition to neuro-immune interactions (Austin and Moalem-Taylor, 2010).
The dorsal horn of the spinal cord receives noxious

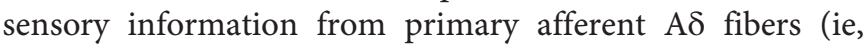
medium diameter myelinated afferents that transmit acute, localized sharp pain sensation) and C fibers (that is, small diameter unmyelinated afferents that convey poorly localized delayed pain sensation) (Braz et al, 2014). The largestdiameter, myelinated primary afferent $\mathrm{A} \beta$ fibers transmit innocuous mechanical stimuli (for example, light touch) and have their terminals in the deeper lamina of the dorsal horn and mainly target excitatory and inhibitory interneurons. On the other hand, the superficial lamina of the dorsal horn is abundant with terminals from $\mathrm{C}$ and $\mathrm{A} \delta$ fibers that activate projection neurons and excitatory interneurons. Under normal conditions, $\mathrm{A} \beta$ fibers do not activate nociceptive projection neurons and do not transmit pain because of strong suppression of signaling by inhibitory interneurons. However, under pathological conditions (that is, peripheral inflammation, or peripheral nerve injury; PNI), neuropathic pain may develop. Nerve injury induces hyperexcitability, thereby causing functional alterations in the neuronal network such as loss of function of inhibitory neurons in the dorsal horn, and results in neuropathic pain (Prescott et al, 2014; Todd, 2010). Additionally, glial cells (innate immune cells of the CNS), which include microglia and astrocytes, contribute to neuropathic pain by altering inflammation and glutamate signaling (Scholz and Woolf, 2007).

Despite recent progress, current mechanistic understanding of pain hypersensitivity caused by nerve damage remains limited. Traditional pain medications generally lack efficacy to treat neuropathic pain (Guirguis-Blake and Kelly, 2007), so a great need exists for the development of new efficacious analgesics. Also, laboratory animal models that accurately mimic key aspects of the pain reported clinically are needed to test candidate therapies. Assessing neuropathic pain behavior in rodents is crucial to validate pain models and new analgesics. Although a wide variety of laboratory animal models of nociception (see Table 1) have been applied to experimental neuropathic and inflammatory pain procedures, these assays generally have limited ability to reflect fully the complexity of clinical symptoms and comorbidities. Nevertheless, pain assessments in these models provide valuable tools for the mechanistic understanding of neuropathic pain syndromes and remain a key step in the discovery process for new pain medications.

Laboratory animal models have been used a variety of preclinical studies investigating cannabinoids in neuropathic pain models. The results of these studies highlight potentially important roles of the endocannabinoid system in the pathophysiology of neuropathic pain, and potential therapeutic targets to treat these conditions (Figures 1 and 2). Using complementary genetic and pharmacological approaches, distinct components of the endocannabinoid system (ie, receptors and endocannabinoid-regulating enzymes) have emerged as promising targets to treat neuropathic pain (Table 5; for additional information, Guindon and Hohmann, 2009; Rahn and Hohmann, 2009). Whether the $\mathrm{CB}_{1}$ receptor plays a tonic role in nociception remains to 
TABLE 5 Antinociceptive Effects of Cannabinoids in Preclinical Models of Neuropathic Pain

\begin{tabular}{|c|c|c|c|c|c|c|c|c|}
\hline \multirow[b]{2}{*}{ Target } & \multirow[b]{2}{*}{ Drug } & \multirow[b]{2}{*}{ Species } & \multicolumn{3}{|c|}{$\begin{array}{l}\text { Anti-allodynic/Anti-hyperalgesic } \\
\text { Stimulus Modality }\end{array}$} & \multicolumn{2}{|c|}{$\begin{array}{l}\text { Receptor Involvement } \\
\text { (Yes/No) }\end{array}$} & \multirow[b]{2}{*}{ Reference(s) } \\
\hline & & & Mechanical & Thermal/Heat & Cold & $\mathrm{CB}_{1}$ & $\mathrm{CB}_{2}$ & \\
\hline \multicolumn{9}{|c|}{ Spinal nerve ligation } \\
\hline \multirow[t]{2}{*}{$C B_{1} \& C_{2}$} & CP55,940 & Mouse, rat & + & & & $\mathrm{Y} / \mathrm{N}$ & Y/N & Sain et al, 2009; Scott et al, 2004 \\
\hline & WIN & Rat & + & + & + & Y & $\mathrm{N}$ & Bridges et al, 200I; LaBuda and Little, 2005; Leichsenring et al, 2009; Yu et al, 2010 \\
\hline \multirow[t]{2}{*}{$\mathrm{CB}_{2}$} & AMI24I & Mouse & + & + & & $\mathrm{N}$ & Y & Beltramo et al, 2006; Hsieh et al, 201 I; Ibrahim et al, 2003 \\
\hline & GW405833 & Rat & + & & & & & Leichsenring et al, 2009 \\
\hline FAAH & URB597 & Rat & + & & & & & de Novellis et al, 201 I \\
\hline \multicolumn{9}{|c|}{ Partial sciatic nerve ligation ( $p S N L$ ) } \\
\hline \multirow{4}{*}{$\mathrm{CB}_{1} \& \mathrm{CB}_{2}$} & AEA & Mouse, rat & + & + & & Y & N & Desroches et al, 20 I 4b; Helyes et al, 2003 \\
\hline & CP55,940 & Rat & + & & & & & Fox et al, 2001 \\
\hline & $\mathrm{HU}-210$ & Rat & + & & & Y & Y & Fox et al, 200 I; Jayamanne et al, 2006; Mitchell et al, 2005; Vuong et al, 2008 \\
\hline & $\mathrm{WIN}$ & Mouse, rat & + & + & + & $\mathrm{Y} / \mathrm{N}$ & Y/N & $\begin{array}{l}\text { Desroches et al, 20 I4b; Fox et al, } 200 \text { I; Guindon et al, 2007; Gunduz et al, 20 I I; } \\
\text { Lever et al, } 2007\end{array}$ \\
\hline \multirow[t]{2}{*}{$\mathrm{CB}_{2}$} & GW405833 & Mouse, rat & + & & & Y & $\mathrm{N}$ & Li et al, 20 I7; Valenzano et al, 2005; Whiteside et al, 2005 \\
\hline & JWHI33 & Mouse & + & & & & Y & Klauke et al, 20 I4; Yamamoto et al, 2008 \\
\hline FAAH & URB597 & Mouse, rat & + & + & & Y & $\mathrm{N}$ & Desroches et al, 2008, 20।4b \\
\hline PPAR $\alpha$ & PEA & Rat & + & & & & Y & Helyes et al, 2003 \\
\hline \multicolumn{9}{|c|}{ Chronic constriction injury (CCl) } \\
\hline \multirow[t]{4}{*}{$C B_{1} \& C_{2}$} & AEA & Rat & + & + & + & Y & & Starowicz et al, 2012 \\
\hline & CP55,940 & Mouse, rat & + & + & & Y & N & Kinsey et al, 20I Ia; De Vry et al, 2004 \\
\hline & $\mathrm{WIN}$ & Mouse, rat & + & + & + & Y & $\mathrm{Y} / \mathrm{N}$ & $\begin{array}{l}\text { Adamson Barnes et al, 2016; Brownjohn and Ashton, 2012; Costa et al, 2004; } \\
\text { Hama and Urban, 2004; Herzberg et al, 1997; Kazantzis et al, 2016; Lim et al, 2003; } \\
\text { Linsell et al, 2015; Liu and Walker, 2006; Pascual et al, 2005; La Rana et al, } 2008\end{array}$ \\
\hline & THC & Mouse, rat & + & + & + & Y & & Kinsey et al, 20 I3; Mao et al, 2000; De Vry et al, 2004; Xie et al, 2016 \\
\hline \multirow[t]{4}{*}{$\mathrm{CB}_{2}$} & AMI24I & Rat & + & & & & & Wilkerson et al, $2012 b$ \\
\hline & AMI7IO & Rat & + & & & & & Wilkerson et al, 2012a \\
\hline & GW405833 & Rat & + & & & & & Brownjohn and Ashton, 2012; Hu et al, 2009 \\
\hline & JWH-0I5 & Mouse & + & + & + & & Y & Hervera et al, 2010 \\
\hline \multirow[t]{3}{*}{ FAAH } & PF-3845 & Mouse, rat & + & & + & Y & Y & $\begin{array}{l}\text { Ghosh et al, 2015; Grim et al, 2014; Kinsey et al, 2010; Malek et al, 2016; Schlosburg } \\
\text { et al, } 2010\end{array}$ \\
\hline & URB597 & Mouse, rat & + & + & + & $\mathrm{Y} / \mathrm{N}$ & Y/N & $\begin{array}{l}\text { Adamson Barnes et al, 2016; Caprioli et al, 20 I2; Kinsey et al, 2009; Russo et al, } \\
\text { 2007; Starowicz et al, 2012, 20 I3; Toniolo et al, } 2014\end{array}$ \\
\hline & URB937 & Mouse & + & + & & Y & $\mathrm{N}$ & Clapper et al, 2010; Sasso et al, 2012 \\
\hline \multirow[t]{2}{*}{ MAGL } & JZLI84 & Mouse, rat & + & + & + & Y & Y/N & $\begin{array}{l}\text { Adamson Barnes et al, 2016; Crowe et al, 2015; Ghosh et al, 2015; Ignatowska- } \\
\text { Jankowska et al, 20 I5a; Kinsey et al, 2009, 20 I0, 20 I3; Schlosburg et al, 20 I0; } \\
\text { Toniolo et al, } 2014\end{array}$ \\
\hline & MJNIIO & Mouse & + & + & & Y & Y/N & Ignatowska-Jankowska et al, 2015a; Wilkerson et al, 2016b \\
\hline
\end{tabular}




\begin{tabular}{|c|c|c|c|c|c|c|c|c|}
\hline \multirow[b]{2}{*}{ Target } & \multirow[b]{2}{*}{ Drug } & \multirow[b]{2}{*}{ Species } & \multicolumn{3}{|c|}{$\begin{array}{c}\text { Anti-allodynic/Anti-hyperalgesic } \\
\text { Stimulus Modality }\end{array}$} & \multicolumn{2}{|c|}{$\begin{array}{c}\text { Receptor Involvement } \\
\text { (Yes/No) }\end{array}$} & \multirow[b]{2}{*}{ Reference(s) } \\
\hline & & & Mechanical & Thermal/Heat & Cold & $\mathrm{CB}_{1}$ & $\mathrm{CB}_{2}$ & \\
\hline \multirow{2}{*}{$\begin{array}{l}\text { Dual FAAH } \\
\text { \& MAGL }\end{array}$} & JZLI95 & Mouse & + & & + & & & Adamson Barnes et al, 2016 \\
\hline & SA-57 & Mouse & + & + & & & & Wilkerson et al, 2017 \\
\hline DAGL $\beta$ & KT- 109 & Mouse & + & + & & & & Wilkerson et al, 2016a \\
\hline PPAR $\alpha$ & PEA & Mouse & + & + & & Y & N & Di Cesare Mannelli et al, 2013; Costa et al, 2008 \\
\hline \multicolumn{9}{|c|}{ Cisplatin-induced peripheral neuropathy } \\
\hline \multirow[t]{3}{*}{$C B_{1} \& C B_{2}$} & AEA & Mouse & + & & & Y & $N$ & Khasabova et al, 2012 \\
\hline & $\mathrm{THC}$ & Mouse & + & & & & & Harris et al, 2016 \\
\hline & $\mathrm{WIN}$ & Rat & + & & & Y & $\mathrm{Y} / \mathrm{N}$ & Vera et al, 2013 \\
\hline \multirow[t]{2}{*}{$\mathrm{CB}_{2}$} & AMI7IO & Rat & + & & + & $\mathrm{N}$ & Y & Deng et al, 2012 \\
\hline & JWHI33 & Rat & + & & & & Y & Vera et al, 2013 \\
\hline \multirow[t]{2}{*}{ FAAH } & URB597 & Mouse, rat & + & & + & Y & $\mathrm{Y} / \mathrm{N}$ & Guindon et al, 2013; Khasabova et al, 2012 \\
\hline & URB937 & Rat & + & & + & Y & Y & Guindon et al, 2013 \\
\hline MAGL & JZLI84 & Mouse, rat & + & & + & Y & $\mathrm{Y} / \mathrm{N}$ & Guindon et al, 20I3; Khasabova et al, 2014 \\
\hline \multicolumn{9}{|c|}{ Paclitaxel-induced peripheral neuropathy } \\
\hline \multirow[t]{3}{*}{$C B_{1} \& C_{2}$} & CP55,940 & Mouse & + & & + & Y & Y & Deng et al, 2015a \\
\hline & WIN & Rat & + & + & & Y & & Pascual et al, 2005 \\
\hline & $\mathrm{THC}$ & Mouse & + & & + & & & Deng et $a l, 2015 b$ \\
\hline \multirow[t]{3}{*}{$\mathrm{CB}_{2}$} & AMI24I & Rat & + & & & $\mathrm{N}$ & Y & Rahn et al, 2008 \\
\hline & AMI7IO & Mouse, rat & + & & + & $\mathrm{N}$ & Y & Deng et $a l, 2012,2015 b$ \\
\hline & AMI7I4 & Rat & + & & & $\mathrm{N}$ & Y & Rahn et al, 2008 \\
\hline DAGL $\beta$ & KT- 109 & Mouse & + & & & & & Wilkerson et al, 2016a \\
\hline PPAR $\alpha$ & PEA & Mouse & + & & & $\mathrm{N}$ & N & Donvito et al, 2016 \\
\hline \multicolumn{9}{|c|}{ Vincristine-induced peripheral neuropathy } \\
\hline $\mathrm{CB}_{1} \& \mathrm{CB}_{2}$ & $\mathrm{WIN}$ & Rat & + & & & Y & Y & Rahn et al, 2007 \\
\hline $\mathrm{CB}_{2}$ & AMI24I & Rat & + & & & $\mathrm{N}$ & Y & Rahn et al, 2007 \\
\hline \multicolumn{9}{|c|}{ Diabetic (streptozotocin-induced) peripheral neuropathy } \\
\hline \multirow[t]{2}{*}{$\mathrm{CB}_{1}$ and $\mathrm{CB}_{2}$} & THC & Mouse, rat & & + & & & & Williams et al, 2008 \\
\hline & $\mathrm{WIN}$ & Mouse, rat & + & + & & $\mathrm{Y} / \mathrm{N}$ & Y & $\begin{array}{l}\text { Bujalska, 2008; Doğrul et al, 2004; lkeda et al, 20 I3; Jahanabadi et al, 20 I6; } \\
\text { Mohammadi-Farani et al, } 20 \text { I 0; Ulugol et al, 2004; Vera et al, 20 I2; Vincenzi et al, } \\
2013\end{array}$ \\
\hline \multirow[t]{2}{*}{$\mathrm{CB}_{2}$} & AMI24I & Rat & + & & & & & Bujalska-Zadrożny et al, 20 I5; Bujalska, 2008 \\
\hline & JWH-0I5 & Mouse & + & + & + & & Y & Castany et al, 2016 \\
\hline $\mathrm{FAAH}$ & URB597 & Rat & + & + & & & & Hasanein et al, 2009 \\
\hline
\end{tabular}




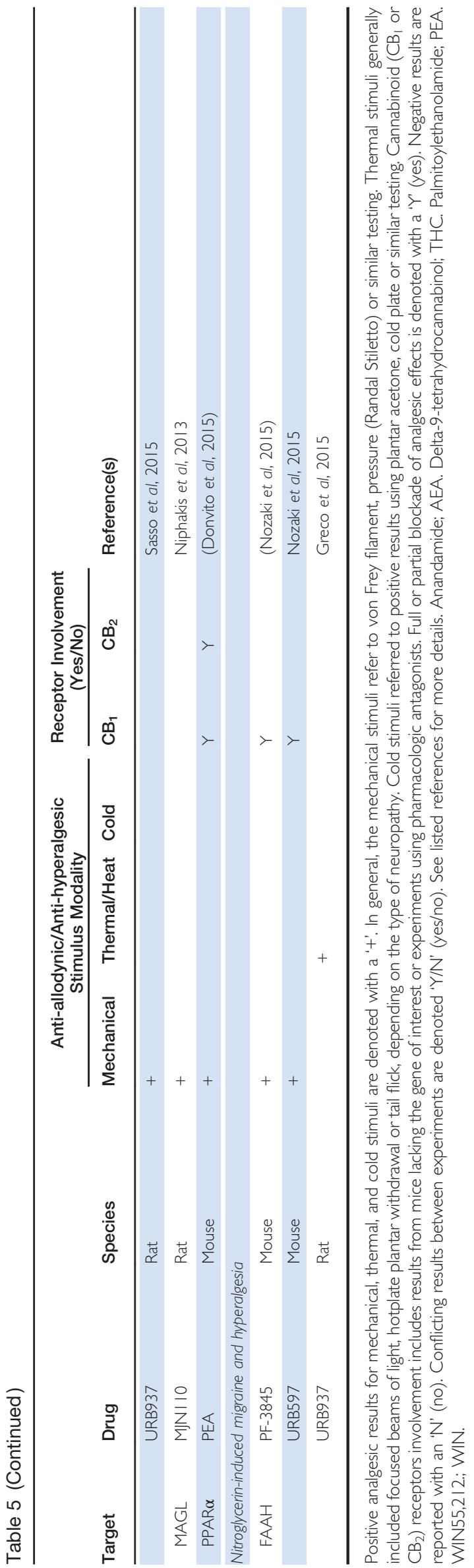

be established. However, it is noteworthy that $\mathrm{CB}_{1}(-/-)$ mice do not display apparent altered nociception (Nadal et al, 2013), but rather a pain-induced increase in time spent in the dark area of the light/dark test, and decreased time and travel distance in the open area of the zero-maze apparatus. Additionally, $\mathrm{CB}_{1}(-/-)$ mice show a reduction in sucrose preference and home cage activity (Rácz et al, 2015). Strikingly, selective $\mathrm{CB}_{1}$ receptor deletion in peripheral nociceptors leads to enhanced pain behavior as well as diminished antinociceptive effects of cannabinoid receptor agonists, suggesting an important role of peripheral $\mathrm{CB}_{1}$ receptors in neuropathic pain (Agarwal et al, 2007).

$\mathrm{CB}_{2}$ receptor deletion also leads to varying effects on neuropathic pain. $\mathrm{CB}_{2}(-/-)$ mice show exacerbated pain behavior, while $\mathrm{CB}_{2}$ overexpression in the CNS attenuates neuropathic pain (Racz et al, 2008). However, other studies using knockout mice or selective inhibitors of $\mathrm{CB}_{1}$ or $\mathrm{CB}_{2}$ receptors show no alterations of nociceptive behavior in neuropathic pain models (Kinsey et al, 2009, 2010) though ceiling effects and other methodological differences between studies may have precluded the detection of enhanced nociceptive behavior. $\mathrm{CB}_{1}$ and $\mathrm{CB}_{2}$ receptor agonists produce antinociceptive effects in laboratory animal models of neuropathic pain (Nadal et al, 2013). On the other hand, the development and expression of neuropathic pain were not modified in FAAH or MAGL $(-/-)$ mice (Nadal et al, 2013; Schlosburg et al, 2010).

This section describes the commonly used models of neuropathic pain: chronic constriction injury (CCI) of the sciatic nerve, streptozotocin (STZ)-induced diabetic neuropathy, chemotherapy-induced neuropathy, and migraine headache. Additionally, we discuss studies reporting the antinociceptive effects of various pharmacological manipulations of the endocannabinoid system in these models.

\section{Nerve Injury Models}

In rodents, one of the most common experimental approaches for inducing peripheral neuropathy is traumatic nerve injury (full or partial) via ligation, transection, or compression of the sciatic nerve (Bennett and Xie, 1988; Seltzer et al, 1990; Wall et al, 1979) or its distal branches (Lee et al, 2000). The partial sciatic nerve ligation model was established by Seltzer, in which approximately half of the rat sciatic nerve is ligated, generally in the proximal region of the thigh, leading to the development of mechanical allodynia and thermal hyperalgesia (Seltzer et al, 1990).

Another well-characterized model is chronic constriction injury (CCI), which inflicts reproducible nerve injury without complete denervation (Bennett and Xie, 1988). Originally developed in rats, one or more sutures are loosely tied around the common sciatic nerve at intervals of 1$2 \mathrm{~mm}$. Rats subjected to CCI show behavioral signs interpreted as spontaneous pain, including moderate autotomy, guarding, licking and, limping of ipsilateral hind paw in addition to avoidance of placing weight on the injured side. 
Within 2 days following surgery, rats show evidence of mechanical allodynia, thermal hyperalgesia and thermal allodynia in the injured paw (Bennett and Xie, 1988). Within three days of surgery, $89 \%$ of $\mathrm{A} \beta, 87 \%$ of $\mathrm{A} \delta$, and $32 \%$ of $\mathrm{C}$ fibers are lost, with progression to loss of $94 \%$ of myelinated fibers and $73 \%$ of unmyelinated fibers within 14 days. Electrophysiological studies have shown that primary afferents, including large-diameter myelinated fibers, spontaneously discharge at ectopic foci proximal to the injury, and these abnormal discharges may contribute to spontaneous and evoked manifestations of neuropathic pain (Munger et al, 1992).

As shown in Table 5 , mixed $\mathrm{CB}_{1} / \mathrm{CB}_{2}$ receptor agonists, $\mathrm{CB}_{1}$-selective receptor agonists, and $\mathrm{CB}_{2}$ receptor-selective agonists suppress increased nociceptive behavior in the CCI, spinal nerve ligation (SNL) and partial sciatic nerve ligation (pSNL) models. In the pSNL rat model, the potency of WIN55,212-2 $(0.1 \mathrm{mg} / \mathrm{kg})$ in decreasing allodynia and hyperalgesia was significantly greater when administered daily prior to the surgery for 7 days, and for the following 2 weeks, than when administered only 2 weeks post-pSNL (Guindon et al, 2007). These findings suggest that activation of cannabinoid receptors can prevent the development of pain induced by nerve injury. In both SNL and pSNL models, the FAAH inhibitor URB597 evoked anti-allodynic (de Novellis et al, 2011), as well as anti-hyperalgesic effects (Desroches et al, 2008, 2014b). In addition, the fatty acid amide PEA, a substrate of FAAH and an endogenous PPAR$\alpha$ ligand, produces antinociceptive effects in a rat pSNL model and in a mouse CCI model (Di Cesare Mannelli et al, 2013; Costa et al, 2008). Interestingly, daily administration of PEA in a mouse model of CCI for a week produces a longlasting reduction of nociceptive behavior in nerve-injured animals after cessation of PEA treatment (Costa et al, 2008).

It is noteworthy that FAAH inhibitors produce antinociceptive effects in the CCI model, without the development of tolerance upon repeated administration (Schlosburg et al, 2010). In contrast, repeated administration of a high dose of the MAGL inhibitor JZL184 leads to tolerance, largely due to $\mathrm{CB}_{1}$ receptor downregulation and desensitization (Schlosburg et al, 2010). However, the antinociceptive effects of a low-dose JZL184 are retained following repeated administration in a mouse model of CCI (Kinsey et al, 2013), suggesting that partial inhibition of MAGL is a viable therapeutic strategy to minimize the likelihood of tolerance. It is important to note that brain levels of 2-AG are approximately three orders of magnitude higher than AEA brain levels (Ahn et al, 2009). Thus, the disparity in tolerance development in mice treated repeatedly with a MAGL inhibitor $v s$ a FAAH inhibitor may be related to differences in mass action of these endocannabinoids. Other possible factors contributing to the differential tolerance include differences in the efficacy of 2-AG and AEA at cannabinoid receptors and differences in $\mathrm{CB}_{1}$ receptor-mediated circuits that these endocannabinoids activate.

The observation that selective inhibition of DAGL- $\beta$, the biosynthetic enzyme expressed predominantly on macrophages and microglia, reduces pro-inflammatory mediators (Hsu et al, 2012), and reverses nociceptive behavior in a mouse model of CCI (Wilkerson et al, 2016a) appears to be at odds with the antinociceptive effects of MAGL inhibitors in this same model. These apparent paradoxical findings were also true in models of inflammatory pain, and can be reconciled when the dual roles of 2-AG are considered. Specifically, as 2-AG is the most highly expressed endocannabinoid in the CNS, it not only plays a major role in cannabinoid receptor activation, but also represents a rate-limiting precursor of arachidonic acid in the CNS and immune cells. Thus, inhibition of 2-AG hydrolysis or biosynthesis on macrophages and microglia results in a reduction of arachidonic acid and proinflammatory metabolites, which can reduce nociceptive behavior through cannabinoid receptor-independent mechanisms.

\section{Streptozotocin-Induced Diabetes}

Insulin-dependent diabetes is thought to cause one of the most prevalent forms of peripheral neuropathy in the developed world (Horowitz, 1993). Diabetic-induced neuropathic pain is difficult to treat and is generally unresponsive to current analgesic therapies. Genetically-based diabetic laboratory animal models include insulin deficient $\mathrm{BB}$ rats and NOD mice, and insulin resistant $o b / o b$ and $d b / d b$ mice. However, the most commonly used model of diabetic neuropathy consists of a single systemic injection of streptozotocin (STZ), which produces progressive and permanent degeneration of the beta cells of the pancreatic islets of Langerhans. This damage to beta cells leads to hyperglycemia, polyuria, polydipsia and weight loss (Katsilambros et al, 1970). STZ-induced diabetes produces consistent, long-lasting thermal and mechanical hyperalgesia, in addition to cold and mechanical allodynia (Courteix et al, 1993), associated with hyperexcitability of nociceptive C fibers in response to mechanical stimuli. Importantly, STZ injection elicits a time-dependent increase in the intensity of hyperalgesia, over a 4 -week observation period. This time course might mimic the slow progression of painful neuropathy in individuals with diabetes from the painful stage to the degenerative and painless stage (Courteix et al, 1993). However, the mechanisms that produce neuropathic pain in this model are still not well understood.

Several studies have demonstrated that THC (Williams et al, 2008) and WIN55,212-2 (Bujalska, 2008; Doğrul et al, 2004; Ikeda et al, 2013; Jahanabadi et al, 2016; MohammadiFarani et al, 2010; Ulugol et al, 2004; Vera et al, 2012; Vincenzi et al, 2013) produce antinociception in rodent STZinduced peripheral neuropathy. In particular, either single or repeated administration of WIN55,212-2 or AM1241, dosedependently attenuated STZ-induced hyperalgesia (Bujalska, 2008). Furthermore, repeated administration for 1 month of medium or high doses of intranasal WIN55,212-2 improved thermal hyperalgesia and mechanical allodynia in STZtreated mice (Toth et al, 2010). In addition, FAAH (Hasanein 
et al, 2009; Sasso et al, 2015) and MAGL (Niphakis et al, 2013) inhibitors reduce nociceptive behavior in STZ-injected rats. Additionally, acute and repeated PEA administration evoked anti-allodynic effects in diabetic mice without the development of tolerance that required the activation of $\mathrm{CB}_{1}$, $\mathrm{CB}_{2}$, TRPV1, PPAR- $\alpha$ and PPAR- $\gamma$ receptors (Donvito et al, 2015) (Table 5).

\section{Chemotherapy-Induced Peripheral Neuropathy}

Chemotherapy-induced peripheral neuropathy (CIPN) is a dose-limiting neurotoxic effect of chemotherapeutic agents used to treat cancer. It is a common cause for early cessation of cancer treatment and affects up to $70 \%$ of patients receiving chemotherapy (Seretny et al, 2014). Patients with CIPN experience symptoms of neuropathic pain such as paraesthesia, dysesthesia, allodynia, and hyperalgesia, in addition to numbness (Boyette-Davis et al, 2013). A wide variety of chemotherapeutic agents, including taxanes, platinum compounds, and vinca alkaloids, elicit similar neurotoxic effects in rodents and patients. These chemotherapeutic agents indirectly induce neuropathy through different mechanisms of action, which result in damage to the dorsal root ganglion satellite cells and Schwann cells that support peripheral nerves. The net effect includes structural damage, loss of peripheral nerve function, and hypersensitivity of remaining nerves. Furthermore, chemotherapeutic agents induce mitochondrial dysfunction and mitochondriamediated oxidative stress, which lead to abnormal nerve functionality and primary afferent neuron terminal or intraepidermal nerve fiber degeneration (Han and Smith, 2013).

Paclitaxel-induced allodynia. Paclitaxel is an extremely efficacious antineoplastic agent for the treatment of solid tumors, but its significant side effects, such as neuropathy, not only decrease quality of life but also can require changes in treatment (Authier et al, 2009). Studies examining different paclitaxel dosing regimens in rodents have led to the development of standard protocols used in preclinical studies. A single injection of paclitaxel $(32 \mathrm{mg} / \mathrm{kg}$, intraperitoneal) in rats produces mechanical and thermal hyperalgesia, but does not elicit mechanical allodynia (Authier et al, 2000). On the other hand, lower doses of paclitaxel (eg, $0.5,1$, or $2 \mathrm{mg} / \mathrm{kg}$, intraperitoneal) administered on alternate days for four injections elicit thermal and mechanical hyperalgesia as well as allodynia to light touch and cold stimuli (Polomano and Bennett, 2001). In rats, behavioral signs of neuropathic pain are accompanied by increased evoked activity and decreased conduction velocity of a subpopulation of $\mathrm{C}$ fibers (Dina et al, 2001).

It has been reported that mixed $\mathrm{CB}_{1} / \mathrm{CB}_{2}$ receptor agonists and $\mathrm{CB}_{2}$ receptor-selective agonists are effective against paclitaxel-induced peripheral neuropathy (Deng et al, 2015a, 2015b; Pascual et al, 2005; Rahn et al, 2008). Notably, chronic low-dose CP55,940 suppressed paclitaxel-induced allodynia in wild-type and $\mathrm{CB}_{2}(-/-)$ mice, but not $\mathrm{CB}_{1}(-/-)$ mice.
By contrast, chronic administration of high-dose of CP55,940 reverses paclitaxel-induced allodynia in $\mathrm{CB}_{1}$ $(-/-)$ mice. However, wild-type paclitaxel-injected mice given 16 days of repeated administration of low-dose of CP55,940 showed tolerance to the anti-allodynic effects. In contrast, selective $\mathrm{CB}_{2}$ receptor agonists produce sustained antinociceptive effects in this model without evidence of tolerance (Deng et al, 2015a). Specifically, repeated systemic administration of the $\mathrm{CB}_{2}$ receptor selective agonist AM1710 suppressed paclitaxel-induced allodynia without tolerance, supporting the potential of prolonged use of $\mathrm{CB}_{2}$ receptor agonists (Deng et al, 2015b). Additionally, selective inhibition of DAGL- $\beta$ dose- and time-dependently reverses mechanical allodynia in paclitaxel-injected mice (Wilkerson et al, 2016a). Likewise, PEA elicited anti-allodynic effects in paclitaxel-treated mice in a PPAR- $\alpha$-dependent manner. Repeated administration of PEA for 7 days did not produce tolerance to its anti-allodynic effects (Donvito et al, 2016) (Table 5).

Cisplatin-induced allodynia. Cisplatin is extensively used alone or in combination with other neurotoxic agents in the treatment of a variety of cancers, including testicular, ovarian, bladder, and lung. Repeated injections of cisplatin in rodents led to increased mechanical and thermal sensitivity (Joseph and Levine, 2009) as well as produced motor disorders (Verdú et al, 1999). Numerous neurophysiologic studies have shown that cisplatin decreases sensory nerve conduction velocities and reduces the amplitude of nerve action potentials (De Koning et al, 1987). Morphologic observations indicate that the nucleolus of primary sensory neurons is severely compromised in experimentally-induced cisplatin neuropathy (Cavaletti et al, 1992). Moreover, cisplatin damages myelinated nerve fibers (Boehmerle et al, 2014). Cisplatin may be expected to accumulate in dorsal root ganglia, leading to nuclear damage and an alteration in the peptide content, and can also exert its neurotoxic effects through Schwann cells (Yamamoto et al, 1997).

Cisplatin administration leads to profound alterations in the endogenous cannabinoid system. Specifically, cisplatin injections alter endocannabinoid tone, upregulating FAAH expression in the dorsal root ganglia (Guindon et al, 2013) (see Table 5). Drugs targeting specific components of the endocannabinoid system produce antinociceptive effects in cisplatin-induced allodynia. For example, AEA, THC, and WIN55,212-2 elicit antinociceptive effects in rodent models of cisplatin-induced peripheral neuropathy through a mechanism of action that requires activation of $\mathrm{CB}_{1}$ (Harris et al, 2016; Khasabova et al, 2012) and $\mathrm{CB}_{2}$ (Vera et al, 2013) receptors. In addition, intraplantar injection of AEA or URB597 transiently attenuated hyperalgesia through activation of peripheral $\mathrm{CB}_{1}$ receptors. The development of cisplatin-induced hyperalgesia was delayed, and its magnitude was reduced, when daily injections of cisplatin were accompanied with URB597. This effect was mediated by the $\mathrm{CB}_{1}$ receptor (Khasabova et al, 2012). Conversely, AM1710 suppressed the maintenance of mechanical and cold 
allodynia in the cisplatin model through a $\mathrm{CB}_{2}$ receptor mechanism of action, with no evidence of $\mathrm{CB}_{1}$ receptor involvement (Deng et al, 2012). Finally, FAAH and MAGL inhibitors reduced cisplatin-induced mechanical and cold allodynia, which are $\mathrm{CB}_{1}$ and $\mathrm{CB}_{2}$ receptors-mediated (Guindon et al, 2013; Khasabova et al, 2014).

Vincristine-induced allodynia. Vincristine is prescribed to treat acute leukemia, neuroblastoma, Hodgkin's disease and other lymphomas. Vincristine arrests mitosis by binding to tubulin and blocking microtubule polymerization. In rats, 10 daily injections of vincristine $(0.02,0.1$, or $0.2 \mathrm{mg} / \mathrm{kg}$, intravenous) with a 2-day drug-free interval after the fifth day, induced hyperalgesia (Aley et al, 1996), and allodynia (Authier et al, 1999). Electrophysiological evaluations showed that vincristine caused decreased conduction velocity in myelinated and unmyelinated fibers and enhanced responsiveness of $\mathrm{C}$ fibers to thermal and mechanical stimuli, but did not change spontaneous activity, activation thresholds, or the number of myelinated and unmyelinated fibers (Tanner et al, 1998). Additionally, vincristine treatment resulted in higher firing frequency and variability in C-fibers, suggesting that alterations of activity-dependent post-synaptic effects in sensory pathways might produce a state of enhanced pain (Tanner et al, 1998).

Mixed $\mathrm{CB}_{1} / \mathrm{CB}_{2}$ receptor agonists and $\mathrm{CB}_{2}$ selective receptor agonists reduce nociceptive behavior in vincristine-treated rats (Rahn et al, 2007) (see Table 5). In particular, systemic administration of WIN55,212-2 suppresses vincristine-evoked mechanical allodynia through a $\mathrm{CB}_{1}$ and $\mathrm{CB}_{2}$-dependent mechanism. In addition, $\mathrm{AM} 1241$ reverses vincristine-induced mechanical hypersensitivity through a $\mathrm{CB}_{2}$ receptor mechanism of action. Spinal administration of WIN55,212-2 suppressed vincristineevoked mechanical hypersensitivity at doses that were inactive following intraplantar administration. These effects were blocked by intrathecal co-administration of rimonabant and SR144528, implicating both $\mathrm{CB}_{1}$ and $\mathrm{CB}_{2}$ receptors (Rahn et al, 2007).

\section{Models of Migraine Headache}

Migraine is a neurological disorder characterized by recurrent debilitating attacks of headache and is the second-most common neurological disorder that accounts for more than half of the number of years lived with disability attributable to neurological diseases (Vos et al, 2012). Chronic migraine occurs when headaches and associated symptoms occur on more than 15 days per month, for at least 3 months, and meet diagnostic criteria for migraine with or without aura on at least 8 days per month (Headache Classification Committee of the International Headache Society (IHS), 2013). Patients with chronic migraine experience pain and other symptoms, including nausea, vomiting, osmophobia, photophobia, and phonophobia in addition to cutaneous allodynia in cranial receptive fields of the ophthalmic division of the trigeminal nerve
(Cooke et al, 2007; Diener et al, 2012). Current animal models of chronic migraine include recurrent activation of the trigeminal nociceptive system by repeated direct or indirect stimulation of the trigeminovascular and meningeal afferents through inflammatory mediators (Melo-Carrillo and Lopez-Avila, 2013) or injection of chemicals (that is, glycerol trinitrate) (Pradhan et al, 2014). Other models are based on genetic modifications (Estevez, 2006), and chronic alteration of the endogenous pain modulating system through serotonin depletion (Cui et al, 2013).

FAAH inhibitors (ie, PF-3845 and URB597) reverse allodynia in a mouse model of nitroglycerin-induced migraine through a $\mathrm{CB}_{1}$ receptor-dependent mechanism (Nozaki et al, 2015). Others have found that the peripherally restricted FAAH inhibitor URB937 administration evoked anti-hyperalgesic effect in rats (Greco et al, 2015). Additionally, $\mathrm{CB}_{2}$ agonism evokes an analgesic effect in a rat model of migraine (Greco et al, 2014) (see Table 5). Another study shows that nitroglycerin-induced hyperalgesia in rats is associated with increased activity of both FAAH and MAGL, and increased density of cannabinoid receptors binding sites in the mesencephalon. In the hypothalamus, the activity of FAAH and the density of cannabinoid binding sites is also enhanced, while in the medulla only the activity of FAAH increases (Greco et al, 2010). AEA also abolishes nitroglycerin-induced hyperalgesia in the phase II of formalin test (Greco et al, 2011). These studies suggest that a dysfunction of the endocannabinoid system may contribute to the development of migraine attacks and modulation of this system can be useful for the treatment of pain associated to migraine.

\section{OPIOID-SPARING EFFECTS: PRECLINICAL STUDIES}

Although opioids are widely accepted for the treatment of chronic pathological pain (Ballantyne and Mao, 2003), recent restructuring of prescription recommendations, particularly within the United States, strongly regulate their dosing (Dowell et al, 2016). These recommendations have arisen due to the epidemic of opioid misuse and abuse, as the use of opioids carries a high abuse potential (Thomas et al, 2015) with prescription opioid misuse preceding $\sim 80 \%$ of new heroin users in the United States (Hedegaard et al, 2015). The combination of opioids with other classes of analgesics is a promising strategy to minimize abuse potential, and other opioid-related side effects (eg, sedation, constipation, physical dependence, tolerance, and respiratory depression) (Benyamin et al, 2008). Indeed, archaeological evidence describes the use of cannabis and opium salve for athletic injury (Bartels et al, 2006). Moreover, preclinical evidence demonstrates co-expression of $\mathrm{CB}_{1}$ receptors and MORs in the periaqueductal gray and the co-administration of HU-210 and morphine into this brain region produces enhanced antinociceptive effects (Wilson-Poe et al, 2012, 2013). $\mathrm{CB}_{1}$ receptors and MORs are also co-expressed within 
the dorsal horn of the spinal cord (Desroches et al, 2014a; da Fonseca Pacheco et al, 2008). Of importance, these receptors share similar signal transduction pathways (Rios et al, 2006). Accordingly, emerging preclinical evidence shows that activation of cannabinoid receptors, via direct actions by $\mathrm{CB}_{1} / \mathrm{CB}_{2}$ agonists, or via MAGL and/or FAAH inhibition, represents a promising opioid-sparing therapeutic option for acute, inflammatory, and neuropathic pain. The reduction in opioid dose is described here as 'opioid-sparing effects'.

\section{Acute Pain Models}

Cannabinoid receptor agonists augment the antinociceptive effects of opioids in preclinical models of acute pain, suggesting that cannabinoid agonists are opioid-sparing (Mecs et al, 2010; Tham et al, 2005; Tuboly et al, 2009). For example, the combination of CP55,940 and morphine synergistically attenuates thermal nociception in mice (Tham et al, 2005). Further, administration of a low dose of THC in combination with morphine prevents tolerance to morphine in the tail flick assay for acute pain (Cichewicz and Welch, 2003). Further studies indicate that the combination of THC and morphine produces synergistic antinociception in the tail flick assay (Cichewicz and McCarthy, 2003). In the hotplate assay for antinociception, pretreatment with CP55,940 $(0.1 \mathrm{mg} / \mathrm{kg})$, a dose that is ineffective by itself, produces a leftward shift in the dose-response of morphine (Miller et al, 2012). Additionally, CP55,940 produces a leftward shift of the morphine dose-response curve in the acetic acid abdominal stretching model of visceral pain in mice (Miller et al, 2012). Similarly, combination of URB597 and morphine produces additive antinociceptive effects in the acetic acid abdominal stretching assay and depressed wheel running in mice (Miller et al, 2012).

In addition to rodent models, combination of opioids and cannabinoids produces enhanced antinociceptive effects in nonhuman primates. Specifically, combined administration of morphine and THC produces augmented antinociceptive effects in the rhesus monkey warm water withdrawal test (Gerak and France, 2016; Li et al, 2008). Subthreshold doses of either CP55,940 or WIN55212-2 produce leftward shifts of the morphine dose-response curve in this assay, but elicit rightward and downward shifts of the morphine dose response curves in the drug discrimination and selfadministration assays (Maguire et al, 2013), suggesting decreased abuse liability. Likewise, subthreshold doses of THC or CP55,940 produce leftward shifts in the antinociceptive dose-response relationships of fentanyl, etorphine, and buprenorphine, with increased shifts for the highefficacy MOR agonists compared with the low-efficacy MOR agonists (Maguire and France, 2014, 2016). In contrast to work conducted on rodents (Smith et al, 2007), the combination of opioids and cannabinoids results in increased antinociceptive tolerance and cross-tolerance to opioids in nonhuman primates (Gerak and France, 2016), which underscores the importance of testing in higher animals. In summary, these studies provide strong evidence that cannabinoids can augment the antinociceptive effects of opioids, which from a translational perspective could be of great benefit to reduce to opioid dosing in pain patients, though the increased rate of tolerance in nonhuman primates presents some concern.

\section{Inflammatory Pain Models}

Cannabinoid receptor agonists significantly decrease the dose of opioids needed to produce antinociception in several models of inflammatory pain, and potentially reduces opioid-induced side-effect profiles such as constipation and depressed respiration. Co-administration of THC and morphine produces synergistic antinociceptive effects in the rat CFA arthritis model (Cox et al, 2007). Several pieces of evidence suggest cross-talk between cannabinoids and the endogenous opioid system. For example, naloxone blocks the antinociceptive effects of THC in both arthritic and nonarthritic rats (Cox and Welch, 2004; Smith et al, 1998). Furthermore, THC attenuates spinal dynorphin levels in arthritic rats, indicating interactions between the opioid and endocannabinoid systems (Cox and Welch, 2004). Few studies are investigating the anatomical site of regulation of opioid-sparing effects under pathological pain conditions. Intrathecal co-administration of the endogenous opioid peptide endomorphin-1 (EM-1) and the endocannabinoid AEA reverses carrageenan-induced thermal hyperalgesia, suggesting a spinal site of action (Tuboly et al, 2009). Combined peripheral administration of the endogenous opioid peptide EM-1 and the endocannabinoid 2-AG attenuates mechanical allodynia produced by intra-articular injection of carrageenan, but did not affect edema (Mecs et al, 2010). Interestingly, a local, intraplantar coadministration of the $\mathrm{CB}_{1}$ receptor agonist arachidonylcyclopropylamide (ACPA) with the mu-opioid receptor agonist DAMGO produces antagonistic effects on each respective compound's antinociceptive properties in the rat CFA model of inflammatory pain (Auh et al, 2016). Finally, co-administration of the $\mathrm{CB}_{2}$ receptor agonist JWH015 and morphine produces synergistic effects in the rat formalin model of inflammatory pain (Grenald et al, 2016).

\section{Neuropathic Pain Models}

Recent evidence supports that cannabinoids are also opioidsparing in models of neuropathic pain. Combination of morphine and the cannabinoid receptor agonist WIN55,212 produces synergistic anti-mechanical and cold allodynia in the mouse CCI model of neuropathic pain but acts in an additive manner in the impairment of motor coordination as assessed with the rotarod assay (Kazantzis et al, 2016). In addition, the co-administration of the $\mathrm{CB}_{2}$ receptor agonist JWH015 and morphine produces synergistic effects in the rat SNI model of neuropathic pain (Grenald et al, 2016).

The MAGL inhibitor MJN110 interacts in a synergistic manner with morphine to reverse allodynia and thermal hyperalgesia in the mouse CCI model, without opioid- 
induced constipation or cannabinoid subjective effects. Importantly, these antinociceptive effects do not undergo tolerance after six days of repeated administration. $\mathrm{CB}_{1}$ receptors, $\mathrm{CB}_{2}$ receptors, and MORs are necessary to produce the observed antinociceptive effects (Wilkerson et al, 2016b). Additionally, SA-57, a dual FAAH-MAGL inhibitor that inhibits FAAH at considerably lower doses than it inhibits MAGL, interacts in an additive manner with morphine to reverse allodynia in the mouse CCI model (Wilkerson et al, 2017), while only producing antinociception in the tetrad assay for cannabimimetic effects. Notably, SA-57 also diminishes drug seeking behavior in mice trained to nose poke for heroin (Wilkerson et al, 2017).

\section{Potential Underlying Mechanisms}

There are several potential underlying neuronal and immunological mechanisms for the opioid-sparing actions of cannabinoids. One intriguing explanation accounting for the effects produced by CBD is that it may act as a positive allosteric modulator of opioid receptors (Kathmann et al, 2006). In addition to the above described influence of the $\mathrm{CB}_{1}$ receptor on neuronal dynorphin release, $\mathrm{CB}_{1}$ receptors and MORs form heterodimers, which account for enhanced neuronal antinociceptive interactions of cannabinoids and opioids (Rios et al, 2006). In the periphery, $\mathrm{CB}_{2}$ receptor agonists lead to endorphin release from keratinocytes (Ibrahim et al, 2005). Moreover, an overwhelming amount of evidence demonstrates that within the CNS, opioid administration leads to the activation of microglia via a toll-like receptor (TLR)-4-dependent mechanism, and produces paradoxical aggravation of proinflammatory immune responses (Hutchinson et al, 2007; Watkins et al, 2009). Although speculative, $\mathrm{CB}_{2}$ receptor agonists may reduce these proinflammatory actions of opioids, thus further enhancing antinociceptive effects. Specifically, it has been found that, within the $\mathrm{CNS}, \mathrm{CB}_{2}$ receptor agonists increase the anti-inflammatory cytokine IL-10, decrease IL-1 $\beta$ (Wilkerson et al, 2012a, 2012b), decrease signaling within the AKT-ERK1/2 pathway (Merighi et al, 2012) and reduce mRNA of monocyte chemoattractant protein 1 (MCP-1)/ CCL2 (Deng et al, 2015a).

In summary, opioid-cannabinoid combinations lead to enhanced antinociception in laboratory animal pain models but do not increase untoward side effects of opioids, such as respiratory depression, abuse liability (Gerak and France, 2016) or constipation (Wilkerson et al, 2016b). Overall, these results indicate that the actions of either direct $\mathrm{CB}_{1} / \mathrm{CB}_{2}$ receptor agonists or the inhibition of endocannabinoid degradative enzymes are a novel therapeutic avenue to decrease the doses of opioids needed for clinical pain control, and warrants further clinical investigation. Indeed, a recent meta-analysis study reported strong evidence that cannabinoids produce opioid-sparing effects in preclinical studies, but only a single study of nine clinical studies provided evidence of opioid-sparing effects in humans (Nielsen $e t$ al, 2017).

\section{CANNABINOIDS AND CLINICAL MANAGEMENT OF PAIN}

A comprehensive meta-analysis shows that medicinal cannabis and cannabinoids effectively alleviate different types of pain, such as neuropathic, fibromyalgia, multiple sclerosis, cancer, diabetic neuropathy, refractory pain due to multiple sclerosis or other neurological conditions, rheumatoid arthritis, noncancer pain, central pain, musculoskeletal problems, and chemotherapy-induced pain (Whiting et al, 2015). Here we highlight relatively recent studies examining the effectiveness of cannabinoids in the clinical management of pain as a number of comprehensive other reviews have recently been published (Lynch and Campbell, 2011; Lynch and Ware, 2015; Stevens and Higgins, 2017).

In studies evaluating smoked cannabis using cigarettes with varying THC contents, significant improvements in pain were observed compared to placebo. In neuropathic pain, cannabis containing both a lower dose (1.29\% THC) and higher dose (3.53 \% THC) delivered by vaporizer demonstrated a significant analgesic response (Wilsey et al, 2013). In a study of multiple sclerosis spasticity and pain, smoked cannabis containing $4 \%$ THC demonstrated a significant anti-spasticity and analgesic effect compared with placebo (Corey-Bloom et al, 2012). A randomized, doubleblinded, placebo controlled study conducted in patients with painful diabetic peripheral neuropathy using different formulation of inhaled cannabis showed a significant dosedependent effect on spontaneous pain score and allodynia (Wallace et al, 2015).

The oromucosal spray Sativex that contains an equal mixture of THC and CBD (approved in Canada and European countries) demonstrated a significant analgesic effect in neuropathic pain (Serpell et al, 2014). In a study involving neuropathic pain in multiple sclerosis patients, Sativex reduced pain compared to placebo at 10 weeks. However, after 14 weeks, there was no difference between oral mucosal cannabis spray and placebo groups (Langford et al, 2013). In a pilot study of chemotherapy-induced neuropathic pain, no statistically significant difference in pain scores was found in the oromucosal-treated group, as compared to the placebo group, although five of the 16 participants reported a 2-point grade reduction of pain score (Lynch et al, 2014). Recently, patients with progressive multiple sclerosis treated with an oral formulation of THC reported a significant reduction of pain (van Amerongen et al, 2017). Notably, this formulation was well tolerated and had a stable pharmacokinetic profile.

Nabilone, a synthetic THC analogue approved by the FDA for treatment of chemotherapy-induced nausea and vomiting (Pertwee, 2012), has also been evaluated for the treatment of pain. In a study of medication overuse headache, nabilone was superior to ibuprofen in reducing daily analgesic intake and pain intensity (Pini et al, 2012). Furthermore, nabilone was significantly more effective than placebo in reducing pain in patients with painful diabetic neuropathy (Toth et al, 2012). In a study using amitriptyline as an active control 
examining sleep with pain as a secondary measure in fibromyalgia, there was no significant pain reduction (Ware et al, 2010). However, nabilone in combination with gabapentin improved pain reporting significantly more than gabapentin alone in multiple sclerosis patients (Turcotte et al, 2015).

A growing body of the preclinical data suggesting that cannabinoids in combination with opioids may lead to increased analgesic effects, while producing opioid-sparing effects in studies evaluating the clinical management of pain. A double-blind study conducted in an experimental pain model involving thermal stimuli applied to normal subjects investigated whether THC potentiates the analgesic effects of morphine (Roberts et al, 2006). In this study, the doses of morphine or THC used alone did not elicit a significant analgesic effect, but combination of the drugs showed an enhanced analgesic effect with respect to the affective component of pain. Indeed, the management of the affective component of pain may be especially relevant to the clinical problem of chronic pain. A phase I, and phase II study examining the efficacy of THC as an adjunct to opioid therapy for the treatment of chronic pain showed that THC enhanced pain relief in patients under opioid therapeutic regimen (Narang et al, 2008).

Although several studies show that 'medical cannabis' can improve various types of pain, cannabimimetic side effects, which include drowsiness or fatigue, dizziness, dry mouth, nausea, and cognitive effects, have also been reported (Whiting et al, 2015). Thus, additional research is needed to improve study methodologies, including the use of standard formulations and/or dosages, the increase in the number of subjects involved, and the general determination of the safe and effective use of cannabis for the treatment of human pain.

At the present time, there is only a single published clinical report examining whether inhibition of an endocannabinoidregulating enzyme relieves pain. In this study, the FAAH inhibitor PF-04457845 failed to relieve pain related to osteoarthritis of the knee, as compared with placebo (Huggins et al, 2012). As FAAH inhibitors produce reliable antinociceptive effects in preclinical osteoarthritis models (Table 4), the lack of translation may be related to species differences or masked by the expectancy effect caused by the placebo in the clinical trial, though the comparison drug naproxen significantly improved pain compared with placebo. Also, it was not explored whether PF-04457845 in combination with naproxen would have resulted in enhanced antinociceptive effects compared with naproxen alone. In light of the death and adverse events in other subjects given repeated high doses of the FAAH inhibitor BIA-102474-101 in a clinical trial (Kerbrat et al, 2016), it is crucial to note that this drug has multitude of off-targets, including inhibition of essential blood-clotting factors thrombin and Factor VII (van Esbroeck et al, 2017; Molinski et al, 2017), which may contributed to its toxicity. It is also important to recognize that the highly selective FAAH inhibitor PF-04457845 was well tolerated in the patients, with no evidence of serious adverse events (Huggins et al, 2012).

\section{CONCLUSIONS AND FUTURE DIRECTIONS}

An overwhelming body of convincing preclinical evidence indicates that cannabinoids produce antinociceptive effects in inflammatory and neuropathic rodent pain models. Cannabinoid receptor agonists, endocannabinoid-regulating enzyme inhibitors, and other pharmacological strategies to manipulate the endogenous cannabinoids system decrease the hyperalgesia and allodynia induced in diverse inflammatory and neuropathic pain states. In particular, the endocannabinoid degradative enzymes FAAH and MAGL are attractive targets for drug development.

The results of clinical studies consistently demonstrate efficacy of cannabis and cannabinoid receptor agonists in reducing diverse neuropathic pain states in humans. However, adverse effects associated with use of 'medical cannabis' as well as challenges in ensuring standardized plant constituents and concerns related to inhaling pyrolysis products of smoked cannabis are large hurdles in developing the entire plant as medicine. Thus, further research is needed to investigate whether other constituents of cannabis besides THC have therapeutic efficacy (for example, CBD) as well as explore safer delivery routes than smoking. Additionally, medicinal chemistry holds great promise to develop cannabimimetic agents that lack cannabimimetic side effects by synthesizing $\mathrm{CB}_{1}$ receptor PAMs, selective $\mathrm{CB}_{2}$ receptor agonists, and selective inhibitors of endocannabinoid regulating enzymes and endocannabinoid transport. Undoubtedly, drug formulation will direct the development of new cannabinoid-based medications. In addition, the combination of cannabinoids with conventional analgesics (for example, opioids, NSAIDs, gabapentin) is a promising avenue by which to increase efficacy and reduce side effects. In sum, the endogenous cannabinoid system contains multiple promising therapeutic targets and provides a strong impetus to develop cannabinoid-based medications to treat inflammatory and neuropathic pain.

\section{FUNDING AND DISCLOSURE}

This research was supported by the National Institutes of Health, National Institute on Drug Abuse [Grants: R01DA039942, P30DA033934, R01DA032933, R03DA038714, R15AR066806, P01DA009789, T32DA007027, F32DA038493, F31NS095628] as well as start-up funds from the VCU School of Pharmacy. The authors declare no conflict of interest.

\section{REFERENCES}

Adamson Barnes NS, Mitchell VA, Kazantzis NP, Vaughan CW (2016). Actions of the dual FAAH/MAGL inhibitor JZL195 in a murine neuropathic pain model. $\mathrm{Br} J$ Pharmacol 173: 77-87.

Agarwal N, Pacher P, Tegeder I, Amaya F, Constantin CE, Brenner GJ et al (2007). Cannabinoids mediate analgesia largely via peripheral type 1 cannabinoid receptors in nociceptors. Nat Neurosci 10: 870-879. 
Ahn K, Johnson DS, Mileni M, Beidler D, Long JZ, McKinney MK et al (2009). Discovery and characterization of a highly selective FAAH inhibitor that reduces inflammatory pain. Chem Biol 16: 411-420.

Ahn K, Smith SE, Liimatta MB, Beidler D, Sadagopan N, Dudley DT et al (2011). Mechanistic and pharmacological characterization of PF-04457845: a highly potent and selective fatty acid amide hydrolase inhibitor that reduces inflammatory and noninflammatory pain. J Pharmacol Exp Ther 338: 114-124.

Aley KO, Reichling DB, Levine JD (1996). Vincristine hyperalgesia in the rat: a model of painful vincristine neuropathy in humans. Neuroscience 73: 259-265.

Anderson WB, Gould MJ, Torres RD, Mitchell VA, Vaughan CW (2014). Actions of the dual FAAH/MAGL inhibitor JZL195 in a murine inflammatory pain model. Neuropharmacology 81: 224-230.

Auh Q-S, Chun YH, Melemedjian OK, Zhang Y, Ro JY (2016). Peripheral interactions between cannabinoid and opioid receptor agonists in a model of inflammatory mechanical hyperalgesia. Brain Res Bull 125: 211-217.

Austin PJ, Moalem-Taylor G (2010). The neuro-immune balance in neuropathic pain: involvement of inflammatory immune cells, immune-like glial cells and cytokines. $\checkmark$ Neuroimmunol 229: 26-50.

Authier N, Balayssac D, Marchand F, Ling B, Zangarelli A, Descoeur J et al (2009). Animal models of chemotherapy-evoked painful peripheral neuropathies. Neurotherapeutics 6: 620-629.

Authier N, Coudore F, Eschalier A, Fialip J (1999). Pain related behaviour during vincristine-induced neuropathy in rats. Neuroreport 10: 965-968.

Authier N, Gillet JP, Fialip J, Eschalier A, Coudore F (2000). Description of a shortterm Taxol-induced nociceptive neuropathy in rats. Brain Res 887: 239-249.

Ballantyne JC, Mao J (2003). Opioid therapy for chronic pain. N Engl J Med 349: 1943-1953.

Bartels EM, Swaddling J, Harrison AP (2006). An ancient Greek pain remedy for athletes. Pain Pract 6: 212-218.

Beltramo M, Bernardini N, Bertorelli R, Campanella M, Nicolussi E, Fredduzzi S et al (2006). CB2 receptor-mediated antihyperalgesia: possible direct involvement of neural mechanisms. Eur J Neurosci 23: 1530-1538.

Bennett GJ, Xie YK (1988). A peripheral mononeuropathy in rat that produces disorders of pain sensation like those seen in man. Pain 33: 87-107.

Benyamin R, Trescot AM, Datta S, Buenaventura R, Adlaka R, Sehgal N et al (2008). Opioid complications and side effects. Pain Physician 11: S105-S120.

Berdyshev EV, Boichot E, Germain N, Allain N, Anger JP, Lagente V (1997). Influence of fatty acid ethanolamides and delta9-tetrahydrocannabinol on cytokine and arachidonate release by mononuclear cells. Eur J Pharmacol 330: 231-240.

Bingham B, Jones PG, Uveges AJ, Kotnis S, Lu P, Smith VA et al (2007). Speciesspecific in vitro pharmacological effects of the cannabinoid receptor 2 (CB2) selective ligand AM1241 and its resolved enantiomers. Br J Pharmacol 151: 1061-1070.

Bisogno T, Howell F, Williams G, Minassi A, Cascio MG, Ligresti A et al (2003). Cloning of the first sn1-DAG lipases points to the spatial and temporal regulation of endocannabinoid signaling in the brain. J Cell Biol 163: 463-468.

Blankman JL, Cravatt BF (2013). Chemical probes of endocannabinoid metabolism. Pharmacol Rev 65: 849-871.

Blankman JL, Simon GM, Cravatt BF (2007). A comprehensive profile of brain enzymes that hydrolyze the endocannabinoid 2-arachidonoylglycerol. Chem Biol 14: 1347-1356.

Boehmerle W, Huehnchen P, Peruzzaro S, Balkaya M, Endres M (2014). Electrophysiological, behavioral and histological characterization of paclitaxel, cisplatin, vincristine and bortezomib-induced neuropathy in C57BI/6 mice. Sci Rep 4: 6370.

Bolognini D, Costa B, Maione S, Comelli F, Marini P, Di Marzo V et al (2010). The plant cannabinoid Delta9-tetrahydrocannabivarin can decrease signs of inflammation and inflammatory pain in mice. $\mathrm{Br} J$ Pharmacol 160: 677-687.

Booker L, Kinsey SG, Abdullah RA, Blankman JL, Long JZ, Ezzili C et al (2012). The fatty acid amide hydrolase (FAAH) inhibitor PF-3845 acts in the nervous system to reverse LPS-induced tactile allodynia in mice. Br J Pharmacol 165: 2485-2496.

Boyette-Davis JA, Cata JP, Driver LC, Novy DM, Bruel BM, Mooring DL et al (2013). Persistent chemoneuropathy in patients receiving the plant alkaloids paclitaxel and vincristine. Cancer Chemother Pharmacol 71: 619-626.

Braz J, Solorzano C, Wang X, Basbaum Al (2014). Transmitting pain and itch messages: a contemporary view of the spinal cord circuits that generate gate control. Neuron 82: 522-536.

Bridges D, Ahmad K, Rice AS (2001). The synthetic cannabinoid WIN55,212-2 attenuates hyperalgesia and allodynia in a rat model of neuropathic pain. $\mathrm{Br} J$ Pharmacol 133: 586-594.

Brownjohn PW, Ashton JC (2012). Spinal cannabinoid CB2 receptors as a target for neuropathic pain: an investigation using chronic constriction injury. Neuroscience 203: 180-193.

Bujalska-Zadrożny M, Cordé Ade, Pawlik K (2015). Influence of nitric oxide synthase or cyclooxygenase inhibitors on cannabinoids activity in streptozotocin-induced neuropathy. Pharmacol Reports 67: 209-216.
Bujalska M (2008). Effect of cannabinoid receptor agonists on streptozotocininduced hyperalgesia in diabetic neuropathy. Pharmacology 82: 193-200.

Burston JJ, Mapp PI, Sarmad S, Barrett DA, Niphakis MJ, Cravatt BF et al (2016). Robust anti-nociceptive effects of monoacylglycerol lipase inhibition in a model of osteoarthritis pain. Br J Pharmacol 173: 3134-3144.

Burston JJ, Sagar DR, Shao P, Bai M, King E, Brailsford L et al (2013). Cannabinoid $\mathrm{CB} 2$ receptors regulate central sensitization and pain responses associated with osteoarthritis of the knee joint. PLOS ONE 8: e80440.

Cabral GA, Griffin-Thomas L (2009). Emerging role of the cannabinoid receptor CB2 in immune regulation: therapeutic prospects for neuroinflammation. Expert Rev Mol Med 11: e3.

Caprioli A, Coccurello R, Rapino C, Di Serio S, Di Tommaso M, Vertechy M et al (2012). The novel reversible fatty acid amide hydrolase inhibitor ST4070 increases endocannabinoid brain levels and counteracts neuropathic pain in different animal models. J Pharmacol Exp Ther 342: 188-195.

Carlezon WA, Chartoff EH (2007). Intracranial self-stimulation (ICSS) in rodents to study the neurobiology of motivation. Nat Protoc 2: 2987-2995.

Castany S, Carcolé M, Leánez S, Pol O (2016). The role of carbon monoxide on the anti-nociceptive effects and expression of cannabinoid 2 receptors during painful diabetic neuropathy in mice. Psychopharmacology 233: 2209-2219.

Cavaletti G, Tredici G, Marmiroli P, Petruccioli MG, Barajon I, Fabbrica D (1992). Morphometric study of the sensory neuron and peripheral nerve changes induced by chronic cisplatin (DDP) administration in rats. Acta Neuropathol 84 364-371.

Cesare Mannelli L, Di, D’Agostino G, Pacini A, Russo R, Zanardelli M, Ghelardini C et al (2013). Palmitoylethanolamide Is a disease-modifying agent in peripheral neuropathy: pain relief and neuroprotection share a PPAR-alpha-mediated mechanism. Mediators Inflamm 2013: 1-12.

Chang YH, Lee ST, Lin WW (2001). Effects of cannabinoids on LPS-stimulated inflammatory mediator release from macrophages: involvement of eicosanoids. J Cell Biochem 81: 715-723.

Choi Y, Yoon YW, Na HS, Kim SH, Chung JM (1994). Behavioral signs of ongoing pain and cold allodynia in a rat model of neuropathic pain. Pain 59: 369-376.

Cichewicz DL, McCarthy EA (2003). Antinociceptive synergy between delta(9)tetrahydrocannabinol and opioids after oral administration. J Pharmacol Exp Ther 304: 1010-1015

Cichewicz DL, Welch SP (2003). Modulation of oral morphine antinociceptive tolerance and naloxone-precipitated withdrawal signs by oral Delta 9tetrahydrocannabinol. J Pharmacol Exp Ther 305: 812-817.

Clapper JR, Moreno-Sanz G, Russo R, Guijarro A, Vacondio F, Duranti A et al (2010). Anandamide suppresses pain initiation through a peripheral endocannabinoid mechanism. Nat Neurosci 13: 1265-1270.

Clayton N, Marshall FH, Bountra C, O'Shaughnessy CT (2002). CB1 and CB2 cannabinoid receptors are implicated in inflammatory pain. Pain 96: 253-260.

Cohen SP, Mao J (2014). Neuropathic pain: mechanisms and their clinical implications. BMJ 348: $\mathrm{f7656.}$

Comelli F, Giagnoni G, Bettoni I, Colleoni M, Costa B (2007). The inhibition of monoacylglycerol lipase by URB602 showed an anti-inflammatory and antinociceptive effect in a murine model of acute inflammation. Br J Pharmacol 152: 787-794.

Cooke L, Eliasziw M, Becker WJ (2007). Cutaneous allodynia in transformed migraine patients. Headache J Head Face Pain 47: 531-539.

Corey-Bloom J, Wolfson T, Gamst A, Jin S, Marcotte TD, Bentley H et al (2012). Smoked cannabis for spasticity in multiple sclerosis: a randomized, placebocontrolled trial. CMAJ 184: 1143-1150.

Costa B, Bettoni I, Petrosino S, Comelli F, Giagnoni G, Di Marzo V (2010). The dual fatty acid amide hydrolase/TRPV1 blocker, $\mathrm{N}$-arachidonoyl-serotonin, relieves carrageenan-induced inflammation and hyperalgesia in mice. Pharmacol Res 61: 537-546.

Costa B, Colleoni M, Conti S, Trovato AE, Bianchi M, Sotgiu ML et al (2004). Repeated treatment with the synthetic cannabinoid WIN 55,212-2 reduces both hyperalgesia and production of pronociceptive mediators in a rat model of neuropathic pain. Br J Pharmacol 141: 4-8

Costa B, Comelli F, Bettoni I, Colleoni M, Giagnoni G (2008). The endogenous fatty acid amide, palmitoylethanolamide, has anti-allodynic and anti-hyperalgesic effects in a murine model of neuropathic pain: involvement of CB(1), TRPV1 and PPARgamma receptors and neurotrophic factors. Pain 139: 541-550.

Courteix C, Eschalier A, Lavarenne J (1993). Streptozocin-induced diabetic rats: behavioural evidence for a model of chronic pain. Pain 53: 81-88.

Cox ML, Haller VL, Welch SP (2007). Synergy between $\Delta$ 9-tetrahydrocannabinol and morphine in the arthritic rat. Eur J Pharmacol 567: 125-130.

Cox ML, Welch SP (2004). The antinociceptive effect of Delta9-tetrahydrocannabinol in the arthritic rat. Eur J Pharmacol 493: 65-74.

Cravatt BF, Demarest K, Patricelli MP, Bracey MH, Giang DK, Martin BR et al (2001). Supersensitivity to anandamide and enhanced endogenous cannabinoid signaling 
in mice lacking fatty acid amide hydrolase. Proc Natl Acad Sci USA 98: 9371-9376.

Cravatt BF, Giang DK, Mayfield SP, Boger DL, Lerner RA, Gilula NB (1996). Molecular characterization of an enzyme that degrades neuromodulatory fattyacid amides. Nature 384: 83-87.

Crowe MS, Leishman E, Banks ML, Gujjar R, Mahadevan A, Bradshaw HB et al (2015). Combined inhibition of monoacylglycerol lipase and cyclooxygenases synergistically reduces neuropathic pain in mice. Br J Pharmacol 172: 1700-1712.

Cui Y, Li Q-H, Yamada H, Watanabe Y, Kataoka Y (2013). Chronic degeneration of dorsal raphe serotonergic neurons modulates cortical spreading depression: a possible pathophysiology of migraine. J Neurosci Res 91: 737-744.

da Fonseca Pacheco D, Klein A, de Castro Perez A, da Fonseca Pacheco CM, de Francischi JN, Duarte IDG (2008). The mu-opioid receptor agonist morphine, but not agonists at delta- or kappa-opioid receptors, induces peripheral antinociception mediated by cannabinoid receptors. $\mathrm{Br} J$ Pharmacol 154: 1143-1149.

D'Amour FE, Smith DL (1941). A method for detemining loo of pain sensation. $J$ Pharmacol Exp Ther 72: 74-79.

De Koning P, Neijt JP, Jennekens FG, Gispen WH (1987). Evaluation of cis-diamminedichloroplatinum (II) (cisplatin) neurotoxicity in rats. Toxicol Appl Pharmacol 89: 81-87.

Deng L, Cornett BL, Mackie K, Hohmann AG (2015a). CB1 knockout mice unveil sustained CB2-mediated antiallodynic effects of the mixed CB1/CB2 agonist cp55,940 in a mouse model of paclitaxel-induced neuropathic pain. Mol Pharmacol 88: 64-74.

Deng L, Guindon J, Cornett BL, Makriyannis A, Mackie K, Hohmann AG (2015b). Chronic cannabinoid receptor 2 activation reverses paclitaxel neuropathy without tolerance or cannabinoid receptor 1-dependent withdrawal. Biol Psychiatry 77: 475-487.

Deng L, Guindon J, Vemuri VK, Thakur GA, White FA, Makriyannis A et al (2012). The maintenance of cisplatin- and paclitaxel-induced mechanical and cold allodynia is suppressed by cannabinoid $\mathrm{CB}_{2}$ receptor activation and independent of CXCR4 signaling in models of chemotherapy-induced peripheral neuropathy. Mol Pain 8: 71 .

de Novellis V, Vita D, Gatta L, Luongo L, Bellini G, De Chiaro M et al (2011). The blockade of the transient receptor potential vanilloid type 1 and fatty acid amide hydrolase decreases symptoms and central sequelae in the medial prefrontal cortex of neuropathic rats. Mol Pain 7: 7.

Desroches J, Bouchard J-F, Gendron L, Beaulieu P (2014a). Involvement of cannabinoid receptors in peripheral and spinal morphine analgesia. Neuroscience 261: 23-42.

Desroches J, Charron S, Bouchard J-F, Beaulieu P (2014b). Endocannabinoids decrease neuropathic pain-related behavior in mice through the activation of one or both peripheral CB1 and CB2 receptors. Neuropharmacology 77: 441-452.

Desroches J, Guindon J, Lambert C, Beaulieu P (2008). Modulation of the antinociceptive effects of 2-arachidonoyl glycerol by peripherally administered FAAH and MGL inhibitors in a neuropathic pain model. Br J Pharmacol 155: 913-924.

Devane WA, Dysarz FA, Johnson MR, Melvin LS, Howlett AC (1988). Determination and characterization of a cannabinoid receptor in rat brain. Mol Pharmacol 34: 605-613.

Devane WA, Hanus L, Breuer A, Pertwee RG, Stevenson LA, Griffin G et al (1992). Isolation and structure of a brain constituent that binds to the cannabinoid receptor. Science 258: 1946-1949.

De Vry J, Kuhl E, Franken-Kunkel P, Eckel G (2004). Pharmacological characterization of the chronic constriction injury model of neuropathic pain. Eur $\mathrm{J}$ Pharmacol 491: 137-148.

Diener H-C, Dodick DW, Goadsby PJ, Lipton RB, Olesen J, Silberstein SD (2012). Chronic migraine-classification, characteristics and treatment. Nat Rev Neuro/ 8: 162-171.

Dina OA, Chen X, Reichling D, Levine JD (2001). Role of protein kinase Cepsilon and protein kinase $A$ in a model of paclitaxel-induced painful peripheral neuropathy in the rat. Neuroscience 108: 507-515.

Dinh TP, Carpenter D, Leslie FM, Freund TF, Katona I, Sensi SL et al (2002). Brain monoglyceride lipase participating in endocannabinoid inactivation. Proc Natl Acad Sci USA 99: 10819-10824.

Doğrul A, Gül H, Yildiz O, Bilgin F, Güzeldemir ME (2004). Cannabinoids blocks tactile allodynia in diabetic mice without attenuation of its antinociceptive effect. Neurosci Lett 368: 82-86.

Donvito G, Bettoni I, Comelli F, Colombo A, Costa B (2015). Palmitoylethanolamide relieves pain and preserves pancreatic islet cells in a murine model of diabetes. CNS Neurol Disord Drug Targets 14: 452-462.

Donvito G, Wilkerson JL, Damaj MI, Lichtman AH (2016). Palmitoylethanolamide reverses paclitaxel-induced allodynia in mice. J Pharmacol Exp Ther 359: 310-318.
Dowell D, Haegerich TM, Chou R (2016). CDC Guideline for prescribing opioids for chronic pain-United States, 2016. JAMA 315: 1624.

Dunn SL, Wilkinson JM, Crawford A, Bunning RAD, Le Maitre CL (2016). Expression of cannabinoid receptors in human osteoarthritic cartilage: implications for future therapies. Cannabis Cannabinoid Res 1: 3-15.

Dunn SL, Wilkinson JM, Crawford A, Le Maitre CL, Bunning RAD (2014). Cannabinoid WIN-55,212-2 mesylate inhibits interleukin-1 $\beta$ induced matrix metalloproteinase and tissue inhibitor of matrix metalloproteinase expression in human chondrocytes. Osteoarthr Cartil 22: 133-144.

Eljaschewitsch E, Witting A, Mawrin C, Lee T, Schmidt PM, Wolf S et al (2006). The endocannabinoid anandamide protects neurons during CNS inflammation by induction of MKP-1 in microglial cells. Neuron 49: 67-79.

Elmes SJR, Winyard LA, Medhurst SJ, Clayton NM, Wilson AW, Kendall DA et al (2005). Activation of $\mathrm{CB} 1$ and CB2 receptors attenuates the induction and maintenance of inflammatory pain in the rat. Pain 118: 327-335.

Estevez M (2006). Invertebrate modeling of a migraine channelopathy. Headache 46 (Suppl 1): S25-S31.

Farquhar-Smith WP, Egertová M, Bradbury EJ, McMahon SB, Rice AS, Elphick MR (2000). Cannabinoid $\mathrm{CB}(1)$ receptor expression in rat spinal cord. Mol Cell Neurosci 15: 510-521.

Fezza F, De Simone C, Amadio D, Maccarrone M (2008). Fatty acid amide hydrolase: a gate-keeper of the endocannabinoid system. Subcell Biochem 49: 101-132.

Fox A, Kesingland A, Gentry C, McNair K, Patel S, Urban L et al (2001). The role of central and peripheral Cannabinoid1 receptors in the antihyperalgesic activity of cannabinoids in a model of neuropathic pain. Pain 92: 91-100.

Fukuda S, Kohsaka H, Takayasu A, Yokoyama W, Miyabe C, Miyabe Y et al (2014). Cannabinoid receptor 2 as a potential therapeutic target in rheumatoid arthritis. BMC Musculoskelet Disord 15: 275.

Gadotti VM, You H, Petrov RR, Berger ND, Diaz P, Zamponi GW (2013). Analgesic effect of a mixed T-type channel inhibitor/CB2 receptor agonist. Mol Pain 9: 32.

Gao Y, Vasilyev DV, Goncalves MB, Howell FV, Hobbs C, Reisenberg M et al (2010). Loss of retrograde endocannabinoid signaling and reduced adult neurogenesis in diacylglycerol lipase knock-out mice. J Neurosci 30: 2017-2024.

Gerak LR, France CP (2016). Combined Treatment with Morphine and $\Delta 9$ Tetrahydrocannabinol in Rhesus Monkeys: Antinociceptive Tolerance and Withdrawal. J Pharmacol Exp Ther 357: 357-366.

Ghosh S, Kinsey SG, Liu Q-S, Hruba L, McMahon LR, Grim TW et al (2015). Full Fatty Acid amide hydrolase inhibition combined with partial monoacylglycerol lipase inhibition: augmented and sustained antinociceptive effects with reduced cannabimimetic side effects in mice. J Pharmacol Exp Ther 354: 111-120.

Ghosh S, Wise LE, Chen Y, Gujjar R, Mahadevan A, Cravatt BF et al (2013). The monoacylglycerol lipase inhibitor JZL184 suppresses inflammatory pain in the mouse carrageenan model. Life Sci 92: 498-505.

Goldring MB, Goldring SR (2007). Osteoarthritis. J Cell Physiol 213: 626-634.

Greco R, Bandiera T, Mangione AS, Demartini C, Siani F, Nappi G et al (2015). Effects of peripheral FAAH blockade on NTG-induced hyperalgesia-evaluation of URB937 in an animal model of migraine. Cephalalgia 35: 1065-1076.

Greco R, Gasperi V, Sandrini G, Bagetta G, Nappi G, Maccarrone M et al (2010). Alterations of the endocannabinoid system in an animal model of migraine: Evaluation in cerebral areas of rat. Cephalalgia 30: 296-302.

Greco R, Mangione AS, Sandrini G, Maccarrone M, Nappi G, Tassorelli C (2011). Effects of anandamide in migraine: data from an animal model. $J$ Headache Pain 12: $177-183$.

Greco R, Mangione AS, Sandrini G, Nappi G, Tassorelli C (2014). Activation of CB2 receptors as a potential therapeutic target for migraine: evaluation in an animal model. J Headache Pain 15: 14

Grenald SA, Young MA, Wang Y, Ossipov MH, Ibrahim MM, Largent-Milnes TM et al (2016). Synergistic attenuation of chronic pain using mu opioid and cannabinoid receptor 2 agonists. Neuropharmacology 116: 59-70.

Grim TW, Ghosh S, Hsu K-L, Cravatt BF, Kinsey SG, Lichtman AH (2014). Combined inhibition of FAAH and COX produces enhanced anti-allodynic effects in mouse neuropathic and inflammatory pain models. Pharmacol Biochem Behav 124: 405-411.

Gui H, Liu X, Liu L-R, Su D-F, Dai S-M (2015). Activation of cannabinoid receptor 2 attenuates synovitis and joint distruction in collagen-induced arthritis. Immunobiology 220: 817-822.

Gui H, Liu X, Wang Z-W, He D-Y, Su D-F, Dai S-M (2014). Expression of cannabinoid receptor 2 and its inhibitory effects on synovial fibroblasts in rheumatoid arthritis. Rheumatology 53: 802-809.

Guindon J, Desroches J, Dani M, Beaulieu P (2007). Pre-emptive antinociceptive effects of a synthetic cannabinoid in a model of neuropathic pain. Eur $J$ Pharmacol 568: 173-176.

Guindon J, Hohmann AG (2009). The endocannabinoid system and pain. CNS Neurol Disord Drug Targets 8: 403-421. 
Guindon J, Lai Y, Takacs SM, Bradshaw HB, Hohmann AG (2013). Alterations in endocannabinoid tone following chemotherapy-induced peripheral neuropathy: effects of endocannabinoid deactivation inhibitors targeting fatty-acid amide hydrolase and monoacylglycerol lipase in comparison to reference analgesics following c. Pharmacol Res 67: 94-109.

Guirguis-Blake J, Kelly C (2007). Are opioids effective in the treatment of neuropathic pain? Am Fam Physician 75: 999-1001.

Gunduz O, Karadag HC, Ulugol A (2011). Synergistic anti-allodynic effects of nociceptin/orphanin FQ and cannabinoid systems in neuropathic mice. Pharmacol Biochem Behav 99: 540-544.

Gutierrez T, Farthing JN, Zvonok AM, Makriyannis A, Hohmann AG (2007). Activation of peripheral cannabinoid $\mathrm{CB}_{1}$ and $\mathrm{CB}_{2}$ receptors suppresses the maintenance of inflammatory nociception: a comparative analysis. $\mathrm{Br} \mathrm{J}$ Pharmacol 150: $153-163$.

Haj CG, Sumariwalla PF, Hanuš L, Kogan NM, Yektin Z, Mechoulam R et al (2015). HU-444, a novel, potent anti-inflammatory, nonpsychotropic cannabinoid. J Pharmacol Exp Ther 355: 66-75.

Hama AT, Urban MO (2004). Antihyperalgesic effect of the cannabinoid agonist WIN55,212-2 is mediated through an interaction with spinal metabotropic glutamate-5 receptors in rats. Neurosci Lett 358: 21-24.

Han Y, Smith MT (2013). Pathobiology of cancer chemotherapy-induced peripheral neuropathy (CIPN). Front Pharmacol 4: 156

Harris HM, Sufka KJ, Gul W, EISohly MA (2016). Effects of delta-9-tetrahydrocannabinol and cannabidiol on cisplatin-induced neuropathy in mice. Planta Med 82: 1169-1172.

Hasanein P, Parviz M, Keshavarz M, Roohbakhsh A (2009). URB597, an inhibitor of fatty acid amide hydrolase, reduces hyperalgesia in diabetic rats. Can J Physiol Pharmacol 87: 432-439.

Headache Classification Committee of the International Headache Society (IHS) (2013). The International Classification of Headache Disorders, 3rd edition (beta version). Cephalalgia 33: 629-808.

Hedegaard H, Chen L-H, Warner M (2015). Drug-poisoning deaths involving heroin: United States, 2000-2013. NCHS Data Brief 1-8. Available at <http://www.ncbi. nlm.nih.gov/pubmed/25932890>.

Helyes Z, Németh J, Thán M, Bölcskei K, Pintér E, Szolcsányi J (2003). Inhibitory effect of anandamide on resiniferatoxin-induced sensory neuropeptide release in vivo and neuropathic hyperalgesia in the rat. Life Sci 73: 2345-2353.

Hervera A, Negrete R, Leánez S, Martín-Campos J, Pol O (2010). The role of nitric oxide in the local antiallodynic and antihyperalgesic effects and expression of delta-opioid and cannabinoid-2 receptors during neuropathic pain in mice. $J$ Pharmacol Exp Ther 334: 887-896.

Herzberg U, Eliav E, Bennett GJ, Kopin IJ (1997). The analgesic effects of R(+)-WIN $55,212-2$ mesylate, a high affinity cannabinoid agonist, in a rat model of neuropathic pain. Neurosci Lett 221: 157-160.

Hohmann AG, Herkenham M (1999). Localization of central cannabinoid CB1 receptor messenger RNA in neuronal subpopulations of rat dorsal root ganglia: a double-label in situ hybridization study. Neuroscience 90: 923-931.

Holt S, Comelli F, Costa B, Fowler CJ (2005). Inhibitors of fatty acid amide hydrolase reduce carrageenan-induced hind paw inflammation in pentobarbital-treated mice: comparison with indomethacin and possible involvement of cannabinoid receptors. Br J Pharmacol 146: 467-476.

Horowitz SH (1993). Diabetic neuropathy. Clin Orthop Relat Res 296: 78-85.

Hsieh GC, Pai M, Chandran P, Hooker BA, Zhu CZ, Salyers AK et al (2011). Central and peripheral sites of action for $\mathrm{CB}_{2}$ receptor mediated analgesic activity in chronic inflammatory and neuropathic pain models in rats. Br J Pharmacol 162: 428-440.

Hsu K-L, Tsuboi K, Adibekian A, Pugh H, Masuda K, Cravatt BF (2012). DAGL $\beta$ inhibition perturbs a lipid network involved in macrophage inflammatory responses. Nat Chem Biol 8: 999-1007.

Hu B, Doods H, Treede R-D, Ceci A (2009). Depression-like behaviour in rats with mononeuropathy is reduced by the CB2-selective agonist GW405833. Pain 143: $206-212$.

Huggins JP, Smart TS, Langman S, Taylor L, Young T (2012). An efficient randomised, placebo-controlled clinical trial with the irreversible fatty acid amide hydrolase-1 inhibitor PF-04457845, which modulates endocannabinoids but fails to induce effective analgesia in patients with pain due to osteoarthritis of the knee. Pain 153: 1837-1846.

Hutchinson MR, Bland ST, Johnson KW, Rice KC, Maier SF, Watkins LR (2007). Opioid-induced glial activation: mechanisms of activation and implications for opioid analgesia, dependence, and reward. Sci World J 7: 98-111.

Ibrahim MM, Deng H, Zvonok A, Cockayne DA, Kwan J, Mata HP et al (2003). Activation of CB2 cannabinoid receptors by AM1241 inhibits experimental neuropathic pain: pain inhibition by receptors not present in the CNS. Proc Nat/ Acad Sci USA 100: 10529-10533.
Ibrahim MM, Porreca F, Lai J, Albrecht PJ, Rice FL, Khodorova A et al (2005). CB2 cannabinoid receptor activation produces antinociception by stimulating peripheral release of endogenous opioids. Proc Natl Acad Sci USA 102: 3093-3098.

Ignatowska-Jankowska B, Wilkerson JL, Mustafa M, Abdullah R, Niphakis M, Wiley $\mathrm{JL}$ et al (2015a). Selective monoacylglycerol lipase inhibitors: antinociceptive versus cannabimimetic effects in mice. J Pharmacol Exp Ther 353: 424-432.

Ignatowska-Jankowska BM, Baillie GL, Kinsey S, Crowe M, Ghosh S, Owens RA et al (2015b). A Cannabinoid CB1 receptor-positive allosteric modulator reduces neuropathic pain in the mouse with no psychoactive effects. Neuropsychopharmacology 40: 2948-2959.

Ignatowska-Jankowska BM, Baillie GL, Kinsey S, Crowe M, Ghosh S, Owens RA et al (2015c). A Cannabinoid CB1 receptor-positive allosteric modulator reduces neuropathic pain in the mouse with no psychoactive effects. Neuropsychopharmacology 40: 2948-2959.

Ignatowska-Jankowska BM, Ghosh S, Crowe MS, Kinsey SG, Niphakis MJ, Abdullah RA et al (2014). In vivo characterization of the highly selective monoacylglycerol lipase inhibitor KML29: antinociceptive activity without cannabimimetic side effects. Br J Pharmacol 171: 1392-1407.

Ikeda H, Ikegami M, Kai M, Onsawa M, Kamei J (2013). Activation of spinal cannabinoid CB2 receptors inhibits neuropathic pain in streptozotocin-induced diabetic mice. Neuroscience 250: 446-454.

Iwamura H, Suzuki H, Ueda Y, Kaya T, Inaba T (2001). In vitro and in vivo pharmacological characterization of JTE-907, a novel selective ligand for cannabinoid CB2 receptor. J Pharmacol Exp Ther 296: 420-425.

Jahanabadi S, Hadian MR, Shamsaee J, Tavangar SM, Abdollahi A, Dehpour A et al (2016). The effect of spinally administered WIN 55,212-2, a cannabinoid agonist, on thermal pain sensitivity in diabetic rats. Iran $J$ Basic Med Sci 19: 394-401.

Jayamanne A, Greenwood R, Mitchell VA, Aslan S, Piomelli D, Vaughan CW (2006). Actions of the FAAH inhibitor URB597 in neuropathic and inflammatory chronic pain models. Br J Pharmacol 147: 281-288.

Jensen TS, Finnerup NB (2014). Allodynia and hyperalgesia in neuropathic pain: clinical manifestations and mechanisms. Lancet Neurol 13: 924-935.

Jhaveri MD, Richardson D, Robinson I, Garle MJ, Patel A, Sun Y et al (2008). Inhibition of fatty acid amide hydrolase and cyclooxygenase-2 increases levels of endocannabinoid related molecules and produces analgesia via peroxisome proliferator-activated receptor-alpha in a model of inflammatory pain. Neuropharmacology 55: 85-93.

Johnson DR, Stebulis JA, Rossetti RG, Burstein SH, Zurier RB (2007). Suppression of fibroblast metalloproteinases by ajulemic acid, a nonpsychoactive cannabinoid acid. J Cell Biochem 100: 184-190.

Joseph EK, Levine JD (2009). Comparison of oxaliplatin- and cisplatin-induced painful peripheral neuropathy in the rat. J Pain 10: 534-541.

Kaczocha M, Glaser ST, Deutsch DG (2009). Identification of intracellular carriers for the endocannabinoid anandamide. Proc Natl Acad Sci 106: 6375-6380.

Kaczocha M, Glaser ST, Maher T, Clavin B, Hamilton J, O'Rourke J et al (2015). Fatty acid binding protein deletion suppresses inflammatory pain through endocannabinoid/N-acylethanolamine-dependent mechanisms. Mol Pain 11: 52.

Kaczocha M, Rebecchi MJ, Ralph BP, Teng Y-HG, Berger WT, Galbavy W et al (2014). Inhibition of fatty acid binding proteins elevates brain anandamide levels and produces analgesia. PLOS ONE 9: e94200.

Karbarz MJ, Luo L, Chang L, Tham C-S, Palmer JA, Wilson SJ et al (2009). Biochemical and biological properties of 4-(3-phenyl-[1,2,4] thiadiazol-5-yl)piperazine-1-carboxylic acid phenylamide, a mechanism-based inhibitor of fatty acid amide hydrolase. Anesth Analg 108: 316-329.

Karouzakis E, Neidhart M, Gay RE, Gay S (2006). Molecular and cellular basis of rheumatoid joint destruction. Immunol Lett 106: 8-13.

Kathmann M, Flau K, Redmer A, Tränkle C, Schlicker E (2006). Cannabidiol is an allosteric modulator at mu- and delta-opioid receptors. Naunyn Schmiedebergs Arch Pharmacol 372: 354-361.

Katsilambros N, Rahman YA, Hinz M, Fussgänger R, Schröder KE, Straub K et al (1970). Action of streptozotocin on insulin and glucagon responses of rat islets. Horm Metab Res 2: 268-270.

Kazantzis NP, Casey SL, Seow PW, Mitchell VA, Vaughan CW (2016). Opioid and cannabinoid synergy in a mouse neuropathic pain model. Br J Pharmacol 173: 2521-2531.

Kerbrat A, Ferré J-C, Fillatre P, Ronzière T, Vannier S, Carsin-Nicol B et al (2016). Acute neurologic disorder from an inhibitor of fatty acid amide hydrolase. N Engl J Med 375: 1717-1725.

Khasabova IA, Khasabov S, Paz J, Harding-Rose C, Simone DA, Seybold VS (2012). Cannabinoid type-1 receptor reduces pain and neurotoxicity produced by chemotherapy. J Neurosci 32: 7091-7101.

Khasabova IA, Yao X, Paz J, Lewandowski CT, Lindberg AE, Coicou L et al (2014). JZL184 is anti-hyperalgesic in a murine model of cisplatin-induced peripheral neuropathy. Pharmacol Res 90: 67-75. 
King KM, Myers AM, Soroka-Monzo AJ, Tuma RF, Tallarida RJ, Walker EA et al (2017). Single and combined effects of $\Delta^{9}$-tetrahydrocannabinol and cannabidiol in a mouse model of chemotherapy-induced neuropathic pain. $\mathrm{Br} J$ Pharmacol 174: 2832-2841.

Kinsey SG, Long JZ, Cravatt BF, Lichtman AH (2010). Fatty acid amide hydrolase and monoacylglycerol lipase inhibitors produce anti-allodynic effects in mice through distinct cannabinoid receptor mechanisms. J Pain 11: 1420-1428.

Kinsey SG, Long JZ, O'Neal ST, Abdullah RA, Poklis JL, Boger DL et al (2009). Blockade of endocannabinoid-degrading enzymes attenuates neuropathic pain. J Pharmacol Exp Ther 330: 902-910.

Kinsey SG, Mahadevan A, Zhao B, Sun H, Naidu PS, Razdan RK et al (2011a). The CB2 cannabinoid receptor-selective agonist $0-3223$ reduces pain and inflammation without apparent cannabinoid behavioral effects. Neuropharmacology 60 : 244-251.

Kinsey SG, Naidu PS, Cravatt BF, Dudley DT, Lichtman AH (2011b). Fatty acid amide hydrolase blockade attenuates the development of collagen-induced arthritis and related thermal hyperalgesia in mice. Pharmacol Biochem Behav 99: $718-725$

Kinsey SG, Wise LE, Ramesh D, Abdullah R, Selley DE, Cravatt BF et al (2013). Repeated low-dose administration of the monoacylglycerol lipase inhibitor JZL184 retains cannabinoid receptor type 1-mediated antinociceptive and gastroprotective effects. J Pharmacol Exp Ther 345: 492-501.

Klauke A-L, Racz I, Pradier B, Markert A, Zimmer AM, Gertsch J et al (2014). The cannabinoid $\mathrm{CB}_{2}$ receptor-selective phytocannabinoid beta-caryophyllene exerts analgesic effects in mouse models of inflammatory and neuropathic pain. Eur Neuropsychopharmacol 24: 608-620.

Klein TW (2005). Cannabinoid-based drugs as anti-inflammatory therapeutics. Nat Rev Immunol 5: 400-411.

Klein TW, Cabral GA (2006). Cannabinoid-induced immune suppression and modulation of antigen-presenting cells. J Neuroimmune Pharmacol 1: 50-64.

Klein TW, Newton CA, Widen R, Friedman $H$ (1985). The effect of delta-9tetrahydrocannabinol and 11-hydroxy-delta-9-tetrahydrocannabinol on T-lymphocyte and B-lymphocyte mitogen responses. J Immunopharmacol 7: 451-466.

Kong Y, Wang W, Zhang C, Wu Y, Liu Y, Zhou X (2016). Cannabinoid WIN-55,212-2 mesylate inhibits ADAMTS-4 activity in human osteoarthritic articular chondrocytes by inhibiting expression of syndecan-1. Mol Med Rep 13: 4569-4576.

LaBuda CJ, Little PJ (2005). Pharmacological evaluation of the selective spinal nerve ligation model of neuropathic pain in the rat. J Neurosci Methods 144: 175-181.

Langford RM, Mares J, Novotna A, Vachova M, Novakova I, Notcutt W et al (2013). A double-blind, randomized, placebo-controlled, parallel-group study of $\mathrm{THC} /$ CBD oromucosal spray in combination with the existing treatment regimen, in the relief of central neuropathic pain in patients with multiple sclerosis. J Neurol 260: 984-997.

La Rana G, Russo R, D’Agostino G, Sasso O, Raso GM, lacono A et al (2008). AM404, an anandamide transport inhibitor, reduces plasma extravasation in a model of neuropathic pain in rat: role for cannabinoid receptors. Neuropharmacology 54: 521-529.

Lee BH, Won R, Baik EJ, Lee SH, Moon CH (2000). An animal model of neuropathic pain employing injury to the sciatic nerve branches. Neuroreport 11: 657-661.

Lehmann C, Fisher NB, Tugwell B, Szczesniak A, Kelly M, Zhou J (2017). Experimental cannabidiol treatment reduces early pancreatic inflammation in type 1 diabetes. Clin Hemorheol Microcirc 64: 655-662.

Leichsenring A, Andriske M, Bäcker I, Stichel CC, Lübbert H (2009). Analgesic and antiinflammatory effects of cannabinoid receptor agonists in a rat model of neuropathic pain. Naunyn Schmiedebergs Arch Pharmacol 379: 627-636.

Lever IJ, Pheby TM, Rice ASC (2007). Continuous infusion of the cannabinoid WIN $55,212-2$ to the site of a peripheral nerve injury reduces mechanical and cold hypersensitivity. Br J Pharmacol 151: 292-302.

Li A-L, Carey LM, Mackie K, Hohmann AG (2017). The cannabinoid CB 2 agonist GW405833 suppresses inflammatory and neuropathic pain through a $\mathrm{CB}_{1}$ mechanism that is independent of $\mathrm{CB}_{2}$ receptors in mice. J Pharmacol Exp Ther 362: 296-305

Li J-X, McMahon LR, Gerak LR, Becker GL, France CP (2008). Interactions between (Delta)9-tetrahydrocannabinol and mu opioid receptor agonists in rhesus monkeys: discrimination and antinociception. Psychopharmacology 199: 199-208.

Lichtman AH, Shelton CC, Advani T, Cravatt BF (2004). Mice lacking fatty acid amide hydrolase exhibit a cannabinoid receptor-mediated phenotypic hypoalgesia. Pain 109: 319-327.

Lim G, Sung B, Ji R-R, Mao J (2003). Upregulation of spinal cannabinoid-1receptors following nerve injury enhances the effects of Win 55,212-2 on neuropathic pain behaviors in rats. Pain 105: 275-283.

Linsell O, Brownjohn PW, Nehoff H, Greish K, Ashton JC (2015). Effect of styrene maleic acid WIN55,212-2 micelles on neuropathic pain in a rat model. J Drug Target 23: 353-359.
Liu C, Walker JM (2006). Effects of a cannabinoid agonist on spinal nociceptive neurons in a rodent model of neuropathic pain. J Neurophysio/ 96: 2984-2994.

Lodzki M, Godin B, Rakou L, Mechoulam R, Gallily R, Touitou E (2003). Cannabidioltransdermal delivery and anti-inflammatory effect in a murine model. $\mathrm{J}$ Control Release 93: 377-387.

Lo Verme JL, Fu J, Astarita G, La Rana G, Russo R, Calignano A et al (2005). The Nuclear Receptor Peroxisome Proliferator-Activated ReceptorMediates the Anti-Inflammatory Actions of Palmitoylethanolamide. Mol Pharmacol 67: 15-19.

Lowin T, Apitz M, Anders S, Straub RH (2015). Anti-inflammatory effects of $\mathrm{N}$-acylethanolamines in rheumatoid arthritis synovial cells are mediated by TRPV1 and TRPA1 in a COX-2 dependent manner. Arthritis Res Ther 17: 321

Lowin T, Pongratz G, Straub RH (2016). The synthetic cannabinoid WIN55,212-2 mesylate decreases the production of inflammatory mediators in rheumatoid arthritis synovial fibroblasts by activating CB2, TRPV1, TRPA1 and yet unidentified receptor targets. J Inflamm (Lond) 13: 15

Lynch ME, Campbell F (2011). Cannabinoids for treatment of chronic non-cancer pain; a systematic review of randomized trials. Br J Clin Pharmacol 72: 735-744.

Lynch ME, Cesar-Rittenberg P, Hohmann AG (2014). A double-blind, placebocontrolled, crossover pilot trial with extension using an oral mucosal cannabinoid extract for treatment of chemotherapy-induced neuropathic pain. J Pain Symptom Manage 47: 166-173.

Lynch ME, Ware MA (2015). Cannabinoids for the treatment of chronic non-cancer pain: An Updated Systematic Review of Randomized Controlled Trials. J Neuroimmune Pharmacol 10: 293-301.

Machelska H, Celik MÖ (2016). Recent advances in understanding neuropathic pain: glia, sex differences, and epigenetics. F1000Res 5: 2743.

Maguire DR, France CP (2014). Impact of efficacy at the $\mu$-opioid receptor on antinociceptive effects of combinations of $\mu$-opioid receptor agonists and cannabinoid receptor agonists. J Pharmacol Exp Ther 351: 383-389.

Maguire DR, France CP (2016). Interactions between cannabinoid receptor agonists and mu opioid receptor agonists in rhesus monkeys discriminating fentanyl. Eur J Pharmacol 784: 199-206.

Maguire DR, Yang W, France CP (2013). Interactions between $\mu$-opioid receptor agonists and cannabinoid receptor agonists in rhesus monkeys: antinociception, drug discrimination, and drug self-administration. J Pharmacol Exp Ther 345: 354-362.

Malek N, Kostrzewa M, Makuch W, Pajak A, Kucharczyk M, Piscitelli F et al (2016). The multiplicity of spinal AA-5-HT anti-nociceptive action in a rat model of neuropathic pain. Pharmacol Res 111: 251-263.

Malek N, Mrugala M, Makuch W, Kolosowska N, Przewlocka B, Binkowski M et al (2015). A multi-target approach for pain treatment: dual inhibition of fatty acid amide hydrolase and TRPV1 in a rat model of osteoarthritis. Pain 156: 890-903.

Malfait AM, Gallily R, Sumariwalla PF, Malik AS, Andreakos E, Mechoulam R et al (2000). The nonpsychoactive cannabis constituent cannabidiol is an oral antiarthritic therapeutic in murine collagen-induced arthritis. Proc Natl Acad Sci USA 97: 9561-9566.

Manning BH, Merin NM, Meng ID, Amaral DG (2001). Reduction in opioid- and cannabinoid-induced antinociception in rhesus monkeys after bilateral lesions of the amygdaloid complex. J Neurosci 21: 8238-8246.

Mao J, Price DD, Lu J, Keniston L, Mayer DJ (2000). Two distinctive antinociceptive systems in rats with pathological pain. Neurosci Lett 280: 13-16.

Marchalant Y, Brownjohn PW, Bonnet A, Kleffmann T, Ashton JC (2014). Validating Antibodies to the Cannabinoid CB2 Receptor: Antibody Sensitivity Is Not Evidence of Antibody Specificity. J Histochem Cytochem 62: 395-404.

Matsuda LA, Lolait SJ, Brownstein MJ, Young AC, Bonner TI (1990). Structure of a cannabinoid receptor and functional expression of the cloned cDNA. Nature 346: 561-564.

Mbvundula EC, Bunning RAD, Rainsford KD (2006). Arthritis and cannabinoids: HU-210 and Win-55,212-2 prevent IL-1alpha-induced matrix degradation in bovine articular chondrocytes in-vitro. J Pharm Pharmacol 58: 351-358.

McCoy KL, Gainey D, Cabral GA (1995). delta 9-Tetrahydrocannabinol modulates antigen processing by macrophages. J Pharmacol Exp Ther 273: 1216-1223.

McKallip RJ, Lombard C, Martin BR, Nagarkatti M, Nagarkatti PS (2002). Delta(9)tetrahydrocannabinol-induced apoptosis in the thymus and spleen as a mechanism of immunosuppression in vitro and in vivo. J Pharmacol Exp Ther 302: 451-465

Mechoulam R, Ben-Shabat S, Hanus L, Ligumsky M, Kaminski NE, Schatz AR et al (1995). Identification of an endogenous 2-monoglyceride, present in canine gut, that binds to cannabinoid receptors. Biochem Pharmacol 50: 83-90.

Mechoulam R, Gaoni Y (1965). A total synthesis of DL-Delta-1-Tetrahydrocannabinol, the active constituent of hashish. J Am Chem Soc 87: 3273-3275.

Mecs L, Tuboly G, Toth K, Nagy E, Nyari T, Benedek G et al (2010). Peripheral antinociceptive effect of 2-arachidonoyl-glycerol and its interaction with endomorphin1 in arthritic rat ankle joints. Clin Exp Pharmacol Physio/ 37: 544-550. 
Melo-Carrillo A, Lopez-Avila A (2013). A chronic animal model of migraine, induced by repeated meningeal nociception, characterized by a behavioral and pharmacological approach. Cephalalgia 33: 1096-1105.

Merighi S, Gessi S, Varani K, Fazzi D, Mirandola P, Borea PA (2012). Cannabinoid $\mathrm{CB}(2)$ receptor attenuates morphine-induced inflammatory responses in activated microglial cells. Br J Pharmacol 166: 2371-2385.

Miller LL, Picker MJ, Umberger MD, Schmidt KT, Dykstra LA (2012). Effects of alterations in cannabinoid signaling, alone and in combination with morphine, on pain-elicited and pain-suppressed behavior in mice. J Pharmacol Exp Ther 342: 177-187.

Mitchell VA, Aslan S, Safaei R, Vaughan CW (2005). Effect of the cannabinoid ajulemic acid on rat models of neuropathic and inflammatory pain. Neurosci Lett 382: 231-235.

Mohammadi-Farani A, Sahebgharani M, Sepehrizadeh Z, Jaberi E, Ghazi-Khansari $M$ (2010). Diabetic thermal hyperalgesia: role of TRPV1 and CB1 receptors of periaqueductal gray. Brain Res 1328: 49-56.

Molinski SV, Shahani VM, MacKinnon SS, Morayniss LD, Laforet M, Woollard G et al (2017). Computational proteome-wide screening predicts neurotoxic drug-protein interactome for the investigational analgesic BIA 10-2474. Biochem Biophys Res Commun 483: 502-508

Munger BL, Bennett GJ, Kajander KC (1992). An experimental painful periphera neuropathy due to nerve constriction. I. Axonal pathology in the sciatic nerve. Exp Neurol 118: 204-214.

Munro S, Thomas KL, Abu-Shaar M (1993). Molecular characterization of a peripheral receptor for cannabinoids. Nature 365: 61-65.

Murphy PG, Ramer MS, Borthwick L, Gauldie J, Richardson PM, Bisby MA (1999). Endogenous interleukin-6 contributes to hypersensitivity to cutaneous stimuli and changes in neuropeptides associated with chronic nerve constriction in mice. Eur J Neurosci 11: 2243-2253.

Nackley AG, Makriyannis A, Hohmann AG (2003). Selective activation of cannabinoid $\mathrm{CB}(2)$ receptors suppresses spinal fos protein expression and pain behavior in a rat model of inflammation. Neuroscience 119: 747-757.

Nadal X, La Porta C, Andreea Bura S, Maldonado R (2013). Involvement of the opioid and cannabinoid systems in pain control: new insights from knockout studies. Eur J Pharmacol 716: 142-157.

Nagarkatti P, Pandey R, Rieder SA, Hegde VL, Nagarkatti M (2009). Cannabinoids as novel anti-inflammatory drugs. Future Med Chem 1: 1333-1349.

Naidu PS, Kinsey SG, Guo TL, Cravatt BF, Lichtman AH (2010). Regulation of Inflammatory Pain by Inhibition of Fatty Acid Amide Hydrolase. J Pharmacol Exp Ther 334: 182-190.

Narang S, Gibson D, Wasan AD, Ross EL, Michna E, Nedeljkovic SS et al (2008). Efficacy of dronabinol as an adjuvant treatment for chronic pain patients on opioid Therapy. J Pain 9: 254-264.

Negrete R, Hervera A, Leánez S, Martín-Campos JM, Pol O (2011). The antinociceptive effects of JWH-015 in chronic inflammatory pain are produced by nitric oxidecGMP-PKG-KATP pathway activation mediated by opioids. PLoS ONE 6: e26688.

Negus SS, Neddenriep B, Altarifi AA, Carroll FI, Leitl MD, Miller LL (2015). Effects of ketoprofen, morphine, and kappa opioids on pain-related depression of nesting in mice. Pain 156: 1

Nielsen S, Sabioni P, Trigo JM, Ware MA, Betz-Stablein BD, Murnion B et al (2017). Opioid-sparing effect of cannabinoids: a systematic review and meta-analysis. Neuropsychopharmacology 42: 1752-1765.

Niphakis MJ, Cognetta AB, Chang JW, Buczynski MW, Parsons LH, Byrne F et al (2013). Evaluation of NHS carbamates as a potent and selective class of endocannabinoid hydrolase inhibitors. ACS Chem Neurosci 4: 1322-1332.

Nomura DK, Morrison BE, Blankman JL, Long JZ, Kinsey SG, Marcondes MCG et al (2011). Endocannabinoid hydrolysis generates brain prostaglandins that promote neuroinflammation. Science 334: 809-813.

Nozaki C, Markert A, Zimmer A (2015). Inhibition of FAAH reduces nitroglycerininduced migraine-like pain and trigeminal neuronal hyperactivity in mice. Eur Neuropsychopharmacol 25: 1388-1396.

O'Callaghan JP, Holtzman SG (1975). Quantification of the analgesic activity of narcotic antagonists by a modified hot-plate procedure. J Pharmacol Exp Ther 192: 497-505

Pascual D, Goicoechea C, Suardíaz M, Martín MI (2005). A cannabinoid agonist, WIN 55,212-2, reduces neuropathic nociception induced by paclitaxel in rats. Pain 118: 23-34

Pertwee RG (2012). Targeting the endocannabinoid system with cannabinoid receptor agonists: pharmacological strategies and therapeutic possibilities. Philos Trans R Soc Lond B Biol Sci 367: 3353-3363.

Pini LA, Guerzoni S, Cainazzo MM, Ferrari A, Sarchielli P, Tiraferri I et al (2012). Nabilone for the treatment of medication overuse headache: results of a preliminary doubleblind, active-controlled, randomized trial. J Headache Pain 13: 677-684.

Piomelli D (2003). The molecular logic of endocannabinoid signalling. Nat Rev Neurosci 4: 873-884.
Polomano RC, Bennett GJ (2001). Chemotherapy-evoked Painful Peripheral Neuropathy. Pain Med 2: 8-14.

Porta C, La, Bura SA, Aracil-Fernández A, Manzanares J, Maldonado R (2013). Role of $\mathrm{CB} 1$ and $\mathrm{CB} 2$ cannabinoid receptors in the development of joint pain induced by monosodium iodoacetate. Pain 154: 160-174.

Pradhan AA, Smith ML, McGuire B, Tarash I, Evans CJ, Charles A (2014). Characterization of a novel model of chronic migraine. Pain 155: 269-274.

Prescott SA, Ma Q, De Koninck Y (2014). Normal and abnormal coding of somatosensory stimuli causing pain. Nat Neurosci 17: 183-191.

Quartilho A, Mata HP, Ibrahim MM, Vanderah TW, Porreca F, Makriyannis A et al (2003). Inhibition of inflammatory hyperalgesia by activation of peripheral CB2 cannabinoid receptors. Anesthesiology 99: 955-960.

Racz I, Nadal X, Alferink J, Banos JE, Rehnelt J, Martin M et al (2008). Crucial role of CB2 cannabinoid receptor in the regulation of central immune responses during neuropathic pain. J Neurosci 28: 12125-12135.

Rácz I, Nent E, Erxlebe E, Zimmer A (2015). CB1 receptors modulate affective behaviour induced by neuropathic pain. Brain Res Bull 114: 42-48.

Rahn EJ, Hohmann AG (2009). Cannabinoids as pharmacotherapies for neuropathic pain: from the bench to the bedside. Neurotherapeutics 6: 713-737.

Rahn EJ, Makriyannis A, Hohmann AG (2007). Activation of cannabinoid CB1 and CB2 receptors suppresses neuropathic nociception evoked by the chemotherapeutic agent vincristine in rats. Br J Pharmacol 152: 765-777.

Rahn EJ, Zvonok AM, Thakur GA, Khanolkar AD, Makriyannis A, Hohmann AG (2008). Selective activation of cannabinoid CB2 receptors suppresses neuropathic nociception induced by treatment with the chemotherapeutic agent paclitaxel in rats. J Pharmacol Exp Ther 327: 584-591.

Randall LO, Selitto JJ (1957). A method for measurement of analgesic activity on inflamed tissue. Arch Int Pharmacodyn Ther 111: 409-419.

Richardson D, Pearson RG, Kurian N, Latif ML, Garle MJ, Barrett DA et al (2008). Characterisation of the cannabinoid receptor system in synovial tissue and fluid in patients with osteoarthritis and rheumatoid arthritis. Arthritis Res Ther 10: R43.

Richardson JD (2000). Cannabinoids modulate pain by multiple mechanisms of action. J Pain 1: 2-14.

Rios C, Gomes I, Devi LA (2006). mu opioid and CB1 cannabinoid receptor interactions: reciprocal inhibition of receptor signaling and neuritogenesis. $\mathrm{Br} J$ Pharmacol 148: 387-395.

Roberts JD, Gennings C, Shih M (2006). Synergistic affective analgesic interaction between delta-9-tetrahydrocannabinol and morphine. Eur J Pharmacol 530: $54-58$

Roux S, Froger C, Porsolt RD, Valverde O, Maldonado R (2003). Place preference test in rodents. Curr Protoc Pharmacol 22:9.15:9.15.1-9.15.14.

Russo R, Loverme J, Rana G, La, Compton TR, Parrott J, Duranti A et al (2007). The fatty acid amide hydrolase inhibitor URB597 (cyclohexylcarbamic acid 3'-carbamoylbiphenyl-3-yl ester) reduces neuropathic pain after oral administration in mice. J Pharmacol Exp Ther 322: 236-242.

Sacerdote P, Massi P, Panerai AE, Parolaro D (2000). In vivo and in vitro treatment with the synthetic cannabinoid CP55, 940 decreases the in vitro migration of macrophages in the rat: involvement of both $\mathrm{CB} 1$ and $\mathrm{CB} 2$ receptors. J Neuroimmunol 109: 155-163.

Sain NMH, Liang A, Kane SA, Urban MO (2009). Antinociceptive effects of the nonselective cannabinoid receptor agonist CP 55,940 are absent in CB1(-/-) and not CB2(-/-) mice in models of acute and persistent pain. Neuropharmacology 57: 235-241.

Sancho R, Calzado MA, Marzo V, Di, Appendino G, Muñoz E (2003). Anandamide inhibits nuclear factor-kappaB activation through a cannabinoid receptorindependent pathway. Mol Pharmacol 63: 429-438.

Sañudo-Peña MC, Strangman NM, Mackie K, Walker JM, Tsou K (1999). CB1 receptor localization in rat spinal cord and roots, dorsal root ganglion, and peripheral nerve. Zhongguo Yao Li Xue Bao 20: 1115-1120.

Sasso O, Bertorelli R, Bandiera T, Scarpelli R, Colombano G, Armirotti A et al (2012). Peripheral FAAH inhibition causes profound antinociception and protects against indomethacin-induced gastric lesions. Pharmacol Res 65: 553-563.

Sasso O, Wagner K, Morisseau C, Inceoglu B, Hammock BD, Piomelli D (2015). Peripheral FAAH and soluble epoxide hydrolase inhibitors are synergistically antinociceptive. Pharmacol Res 97: 7-15.

Schlosburg JE, Blankman JL, Long JZ, Nomura DK, Pan B, Kinsey SG et al (2010). Chronic monoacylglycerol lipase blockade causes functional antagonism of the endocannabinoid system. Nat Neurosci 13: 1113-1119.

Scholz J, Woolf CJ (2007). The neuropathic pain triad: neurons, immune cells and glia. Nat Neurosci 10: 1361-1368.

Schuelert N, Johnson MP, Oskins JL, Jassal K, Chambers MG, McDougall J J (2011). Local application of the endocannabinoid hydrolysis inhibitor URB597 reduces nociception in spontaneous and chemically induced models of osteoarthritis. Pain 152: 975-981. 
Scott DA, Wright CE, Angus JA (2004). Evidence that CB-1 and CB-2 cannabinoid receptors mediate antinociception in neuropathic pain in the rat. Pain 109: 124-131.

Seltzer Z, Dubner R, Shir Y (1990). A novel behavioral model of neuropathic pain disorders produced in rats by partial sciatic nerve injury. Pain 43: 205-218.

Selvi E, Lorenzini S, Garcia-Gonzalez E, Maggio R, Lazzerini PE, Capecchi PL et al (2008). Inhibitory effect of synthetic cannabinoids on cytokine production in rheumatoid fibroblast-like synoviocytes. Clin Exp Rheumatol 26: 574-581.

Seretny M, Currie GL, Sena ES, Ramnarine S, Grant R, MacLeod MR et al (2014). Incidence, prevalence, and predictors of chemotherapy-induced peripheral neuropathy: A systematic review and meta-analysis. Pain 155: 2461-2470.

Serpell M, Ratcliffe S, Hovorka J, Schofield M, Taylor L, Lauder H et al (2014). A double-blind, randomized, placebo-controlled, parallel group study of THC/CBD spray in peripheral neuropathic pain treatment. Eur J Pain 18: 999-1012.

Smith FL, Fujimori K, Lowe J, Welch SP (1998). Characterization of delta9tetrahydrocannabinol and anandamide antinociception in nonarthritic and arthritic rats. Pharmacol Biochem Behav 60: 183-191.

Smith PA, Selley DE, Sim-Selley LJ, Welch SP (2007). Low dose combination of morphine and delta9-tetrahydrocannabinol circumvents antinociceptive tolerance and apparent desensitization of receptors. Eur J Pharmacol 571: 129-137.

Sofia RD, Nalepa SD, Harakal JJ, Vassar HB (1973). Anti-edema and analgesic properties of delta9-tetrahydrocannabinol (THC). J Pharmacol Exp Ther 186: 646-655.

Sophocleous A, Börjesson AE, Salter DM, Ralston SH (2015). The type 2 cannabinoid receptor regulates susceptibility to osteoarthritis in mice. Osteoarthr Cartil 23: 1586-1594.

Starowicz K, Makuch W, Korostynski M, Malek N. Slezak M, Zychowska M et al (2013). Full inhibition of spinal FAAH leads to TRPV1-mediated analgesic effects in neuropathic rats and possible lipoxygenase-mediated remodeling of anandamide metabolism. PLOS ONE 8: e60040.

Starowicz K, Makuch W, Osikowicz M, Piscitelli F, Petrosino S, Di Marzo V et al (2012). Spinal anandamide produces analgesia in neuropathic rats: possible CB (1)- and TRPV1-mediated mechanisms. Neuropharmacology 62: 1746-1755.

Stevens AJ, Higgins MD (2017). A systematic review of the analgesic efficacy of cannabinoid medications in the management of acute pain. Acta Anaesthesiol Scand 61: 268-280.

Sugiura T, Kondo S, Sukagawa A, Nakane S, Shinoda A, Itoh K et al (1995). 2Arachidonoylgylcerol: a possible endogenous cannabinoid receptor ligand in brain. Biochem Biophys Res Commun 215: 89-97.

Sumariwalla PF, Gallily R, Tchilibon S, Fride E, Mechoulam R, Feldmann M (2004). A novel synthetic, nonpsychoactive cannabinoid acid (HU-320) with antiinflammatory properties in murine collagen-induced arthritis. Arthritis Rheum 50: 985-998.

Tanimura A, Yamazaki M, Hashimotodani Y, Uchigashima M, Kawata S, Abe M et al (2010). The Endocannabinoid 2-Arachidonoylglycerol produced by diacylglycerol lipase $\alpha$ mediates retrograde suppression of synaptic transmission. Neuron 65 : 320-327.

Tanner KD, Reichling DB, Levine JD (1998). Nociceptor hyper-responsiveness during vincristine-induced painful peripheral neuropathy in the rat. J Neurosci 18: 6480-6491.

Tham SM, Angus JA, Tudor EM, Wright CE (2005). Synergistic and additive interactions of the cannabinoid agonist CP55,940 with mu opioid receptor and alpha2-adrenoceptor agonists in acute pain models in mice. Br J Pharmacol 144: 875-884.

Thomas D, Frascella J, Hall T, Smith W, Compton W, Koroshetz W et al (2015). Reflections on the role of opioids in the treatment of chronic pain: a shared solution for prescription opioid abuse and pain. J Intern Med 278: 92-94.

Todd AJ (2010). Neuronal circuitry for pain processing in the dorsal horn. Nat Rev Neurosci 11: 823-836.

Toniolo EF, Maique ET, Ferreira WA, Heimann AS, Ferro ES, Ramos-Ortolaza DL et al (2014). Hemopressin, an inverse agonist of cannabinoid receptors, inhibits neuropathic pain in rats. Peptides 56: 125-131.

Toth C, Mawani S, Brady S, Chan C, Liu C, Mehina E et al (2012). An enrichedenrolment, randomized withdrawal, flexible-dose, double-blind, placebo-controlled, parallel assignment efficacy study of nabilone as adjuvant in the treatment of diabetic peripheral neuropathic pain. Pain 153: 2073-2082.

Toth CC, Jedrzejewski NM, Ellis CL, Frey WH (2010). Cannabinoid-mediated modulation of neuropathic pain and microglial accumulation in a model of murine type I diabetic peripheral neuropathic pain. Mol Pain 6: 16.

Tsou K, Brown S, Sañudo-Peña MC, Mackie K, Walker JM (1998). Immunohistochemical distribution of cannabinoid $\mathrm{CB} 1$ receptors in the rat central nervous system. Neuroscience 83: 393-411.

Tuboly G, Mecs L, Benedek G, Horvath G (2009). Antinociceptive interactions between anandamide and endomorphin-1 at the spinal level. Clin Exp Pharmacol Physio/ 36: 400-405.
Turcotte D, Doupe M, Torabi M, Gomori A, Ethans K, Esfahani F et al (2015). Nabilone as an adjunctive to gabapentin for multiple sclerosis-induced neuropathic pain: a randomized controlled trial. Pain Med 16: 149-159.

Ulugol A, Karadag HC, Ipci Y, Tamer M, Dokmeci I (2004). The effect of WIN 55,2122, a cannabinoid agonist, on tactile allodynia in diabetic rats. Neurosci Lett 371 : 167-170.

Valenzano KJ, Tafesse L, Lee G, Harrison JE, Boulet JM, Gottshall SL et al (2005). Pharmacological and pharmacokinetic characterization of the cannabinoid receptor 2 agonist, GW405833, utilizing rodent models of acute and chronic pain, anxiety, ataxia and catalepsy. Neuropharmacology 48: 658-672.

van Amerongen G, Kanhai K, Baakman AC, Heuberger J, Klaassen E, Beumer TL et al (2017). Effects on spasticity and neuropathic pain of an oral formulation of $\Delta 9$-tetrahydrocannabinol in patients with progressive multiple sclerosis. Clin Ther (doi: 10.1016/j.clinthera.2017.01.016; e-pub ahead of print). van Esbroeck ACM, Janssen APA, Cognetta AB, Ogasawara D, Shpak G, van der Kroeg M et al (2017). Activity-based protein profiling reveals off-target proteins of the FAAH inhibitor BIA 10-2474. Science 356: 1084-1087.

Vera G, Cabezos PA, Martín MI, Abalo R (2013). Characterization of cannabinoidinduced relief of neuropathic pain in a rat model of cisplatin-induced neuropathy. Pharmacol Biochem Behav 105: 205-212.

Vera G, López-Miranda V, Herradón E, Martín MI, Abalo R (2012). Characterization of cannabinoid-induced relief of neuropathic pain in rat models of type 1 and type 2 diabetes. Pharmacol Biochem Behav 102: 335-343.

Verdú E, Vilches JJ, Rodríguez FJ, Ceballos D, Valero A, Navarro X (1999). Physiological and immunohistochemical characterization of cisplatin-induced neuropathy in mice. Muscle Nerve 22: 329-340.

Vincenzi F, Targa M, Corciulo C, Tabrizi MA, Merighi S, Gessi S et al (2013). Antinociceptive effects of the selective CB2 agonist MT178 in inflammatory and chronic rodent pain models. Pain 154: 864-873.

Vivian JA, Kishioka S, Butelman ER, Broadbear J, Lee KO, Woods JH (1998). Analgesic, respiratory and heart rate effects of cannabinoid and opioid agonists in rhesus monkeys: antagonist effects of SR 141716A. J Pharmacol Exp Ther 286: 697-703.

Vos T, Flaxman AD, Naghavi M, Lozano R, Michaud C, Ezzati M et al (2012). Years lived with disability (YLDs) for 1160 sequelae of 289 diseases and injuries 19902010: a systematic analysis for the Global Burden of Disease Study 2010. Lancet 380: 2163-2196.

Vuong LAQ, Mitchell VA, Vaughan CW (2008). Actions of $\mathrm{N}$-arachidonyl-glycine in a rat neuropathic pain model. Neuropharmacology 54: 189-193.

Wall PD, Devor M, Inbal R, Scadding JW, Schonfeld D, Seltzer Z et al (1979). Autotomy following peripheral nerve lesions: experimental anaesthesia dolorosa. Pain 7: 103-111.

Wallace MS, Marcotte TD, Umlauf A, Gouaux B, Atkinson JH (2015). Efficacy of inhaled cannabis on painful diabetic neuropathy. J Pain 16: 616-627.

Ward SJ, McAllister SD, Kawamura R, Murase R, Neelakantan H, Walker EA (2014). Cannabidiol inhibits paclitaxel-induced neuropathic pain through 5-HT 1 A receptors without diminishing nervous system function or chemotherapy efficacy. Br J Pharmacol 171: 636-645.

Ware MA, Fitzcharles M-A, Joseph L, Shir Y (2010). The effects of nabilone on sleep in fibromyalgia: results of a Randomized Controlled Trial. Anesth Analg 110: 604-610.

Watkins LR, Hutchinson MR, Rice KC, Maier SF (2009). The "toll" of opioid-induced glial activation: improving the clinical efficacy of opioids by targeting glia. Trends Pharmacol Sci 30: 581-591.

Whiteside GT, Gottshall SL, Boulet JM, Chaffer SM, Harrison JE, Pearson MS et al (2005). A role for cannabinoid receptors, but not endogenous opioids, in the antinociceptive activity of the CB2-selective agonist, GW405833. Eur J Pharmacol 528: 65-72.

Whiting PF, Wolff RF, Deshpande S, Di Nisio M, Duffy S, Hernandez AV et al (2015). Cannabinoids for medical use. JAMA 313: 2456.

Wilkerson JL, Gentry KR, Dengler EC, Wallace JA, Kerwin AA, Armijo LM et al (2012a). Intrathecal cannabilactone CB(2)R agonist, AM1710, controls pathological pain and restores basal cytokine levels. Pain 153: 1091-1106.

Wilkerson JL, Gentry KR, Dengler EC, Wallace JA, Kerwin AA, Kuhn MN et al (2012b). Immunofluorescent spectral analysis reveals the intrathecal cannabinoid agonist, AM1241, produces spinal anti-inflammatory cytokine responses in neuropathic rats exhibiting relief from allodynia. Brain Behav 2: 155-177.

Wilkerson JL, Ghosh S, Bagdas D, Mason BL, Crowe MS, Hsu KL et al (2016a). Diacylglycerol lipase $\beta$ inhibition reverses nociceptive behaviour in mouse models of inflammatory and neuropathic pain. $\mathrm{Br} J$ Pharmacol 173: 1678-1692.

Wilkerson JL, Ghosh S, Mustafa M, Abdullah RA, Niphakis MJ, Cabrera R et al (2017). The endocannabinoid hydrolysis inhibitor SA-57: Intrinsic antinociceptive effects, augmented morphine-induced antinociception, and attenuated heroin seeking behavior in mice. Neuropharmacology 114: 156-167. 
Wilkerson JL, Niphakis MJ, Grim TW, Mustafa MA, Abdullah RA, Poklis JL et al (2016b). The selective monoacylglycerol lipase inhibitor MJN110 produces opioid-sparing effects in a mouse neuropathic pain model. J Pharmacol Exp Ther 357: 145-156.

Williams J, Haller VL, Stevens DL, Welch SP (2008). Decreased basal endogenous opioid levels in diabetic rodents: effects on morphine and delta-9-tetrahydrocannabinoid-induced antinociception. Eur J Pharmacol 584: 78-86.

Wilsey B, Marcotte T, Deutsch R, Gouaux B, Sakai S, Donaghe H (2013). Low-dose vaporized cannabis significantly improves neuropathic pain. J Pain 14: 136-148.

Wilson-Poe AR, Morgan MM, Aicher SA, Hegarty DM (2012). Distribution of CB1 cannabinoid receptors and their relationship with mu-opioid receptors in the rat periaqueductal gray. Neuroscience 213: 191-200.

Wilson-Poe AR, Pocius E, Herschbach M, Morgan MM (2013). The periaqueductal gray contributes to bidirectional enhancement of antinociception between morphine and cannabinoids. Pharmacol Biochem Behav 103: 444-449.

Wise LE, Cannavacciulo R, Cravatt BF, Martin BF, Lichtman AH (2008). Evaluation of fatty acid amides in the carrageenan-induced paw edema model. Neuropharmacology 54: 181-188.

Xie J, Xiao D, Zhao J, Hu N, Bao Q, Jiang L et al (2016). Mesoporous Silica Particles as a Multifunctional Delivery System for Pain Relief in Experimental Neuropathy. Adv Healthc Mater 5: 1213-1221.

Xiong W, Cui T, Cheng K, Yang F, Chen S-R, Willenbring D et al (2012). Cannabinoids suppress inflammatory and neuropathic pain by targeting $\alpha 3$ glycine receptors. J Exp Med 209: 1121-1134.
Yamamoto M, Kachi T, Yamada T, Nagamatsu M, Sobue G (1997). Sensory conduction study of cisplatin neuropathy: preservation of small myelinated fibers. Intern Med 36: 829-833.

Yamamoto W, Mikami T, Iwamura H (2008). Involvement of central cannabinoid CB2 receptor in reducing mechanical allodynia in a mouse model of neuropathic pain. Eur J Pharmacol 583: 56-61.

Yao BB, Hsieh G, Daza AV, Fan Y, Grayson GK, Garrison TR et al (2009). Characterization of a cannabinoid CB2 receptor-selective agonist, A-836339 [2,2,3,3-tetramethyl-cyclopropanecarboxylic acid [3-(2-methoxyethyl)-4,5-dimethyl-3H-thiazol-(2Z)-ylidene]-amide], using in vitro pharmacological assays, in vivo pain models, and pharmacological magnetic resonance imaging. J Pharmacol Exp Ther 328: 141-151.

Yao BB, Hsieh GC, Frost JM, Fan Y, Garrison TR, Daza AV et al (2008). In vitro and in vivo characterization of A-796260: a selective cannabinoid CB2 receptor agonist exhibiting analgesic activity in rodent pain models. Br J Pharmacol 153: 390-401.

Yu XH, Cao CQ, Martino G, Puma C, Morinville A, St-Onge S et al (2010). A peripherally restricted cannabinoid receptor agonist produces robust antinociceptive effects in rodent models of inflammatory and neuropathic pain. Pain 151: $337-344$.

Yuan M, Kiertscher SM, Cheng Q, Zoumalan R, Tashkin DP, Roth MD (2002). Delta 9-Tetrahydrocannabinol regulates Th1/Th2 cytokine balance in activated human T cells. J Neuroimmunol 133: 124-131.

Zurier RB, Rossetti RG, Lane JH, Goldberg JM, Hunter SA, Burstein SH (1998). Dimethylheptyl-THC-11 OIC acid: a nonpsychoactive antiinflammatory agent with a cannabinoid template structure. Arthritis Rheum 41: 163-170. 